Phonology 38 (2021) 611-650. (C) The Author(s), 2022. Published by Cambridge University Press. This is an Open Access article, distributed under the terms of the Creative Commons Attribution licence (https://creativecommons.org/licenses/by/4.0/), which permits unrestricted re-use, distribution, and reproduction in any medium, provided the original work is properly cited. doi:10.1017/S0952675721000348

\title{
Dominance is
}

\section{non-representational: evidence from A'ingae verbal stress*}

\author{
Maksymilian Dąbkowski \\ University of California, Berkeley
}

\begin{abstract}
A'ingae (or Cofán) is a language isolate spoken in the Ecuadorian and Colombian Amazon. This study presents a description and analysis of the language's morphologically conditioned verbal stress assignment. Specifically, I show that A'ingae verbal morphemes can be classified with two binary parameters: the presence or absence of prestressing and the presence or absence of stress deletion (i.e. dominance), which vary independently. I formalise my analysis in Cophonology Theory, a non-representational theory of the phonologymorphology interface, which captures morpheme-specific phonology with constraint rankings particularised to morphological constructions. I argue that while non-representational approaches such as Cophonology Theory can handle the facts of A'ingae stress deletion straightforwardly, representational approaches lack the expressive power necessary to capture the stress facts of the language.
\end{abstract}

\section{Introduction}

Phonological alternations are not always fully general in a language; certain phonological effects may show up only in certain morphological contexts, resulting in morpheme-specific phonology. Morpheme-specific phonology is well-attested typologically, with the phonological grammars of most (if

* E-mail: MAKSYMilian.Michal.DABKowski@GMAiL.CoM.

First of all, my heartfelt thanks to my Cofán collaborators, who have welcomed me to their community and shared their language with me. Thanks especially to Jorge Mendua, Shen Aguinda, Hugo Lucitante, Leidy Quenamá and Raúl Quieta for the kindness and generosity they treated me with. I would also like to thank Hannah Sande, Larry Hyman, Scott AnderBois, Peter Jenks, Lev Michael, Myriam Lapierre, Zachary O’Hagan, John Starr, Sam Liff, Wilson Silva, Uriel Cohen Priva, Gašper Beguš, Roman Feiman, Chelsea Sanker, Donca Steriade, Adam Albright, Kalinda Pride, Phonology reviewers and editors, and audiences at various conferences and meetings for helpful discussions and their invaluable feedback. My research was supported in part by a Royce Fellowship grant for the project 'A'ingae language preservation' and an Oswalt Endangered Language Grant for the project 'Phonology-syntax interface in A'ingae'. 


\section{Maksymilian Dabkowski}

not all) languages displaying some degree of morphological sensitivity (Sande 2020). Due to competing perspectives on the nature of morphologically conditioned phonology, it continues to play an important role in developing theories of the phonology-morphology interface.

One may broadly divide approaches to morpheme-specific phonology into two categories: representational and non-representational. Representational approaches attribute morpheme-specific phonological processes to differences in the underlying symbolic representations of these morphemes. Prominent representational tools include featural underspecification, autosegmental and metrical representations (Goldsmith 1976, Hayes 1995, Jaker \& Kiparsky 2020), segmentally empty prosodic nodes (Samek-Lodovici 1994, Saba Kirchner 2010, Bermúdez-Otero 2012, van Oostendorp 2012, Trommer \& Zimmermann 2014) and gradient symbolic representations (Rosen 2016, Smolensky \& Goldrick 2016, Zimmermann 2018, 2019, Kushnir 2019).

Non-representational approaches, on the other hand, associate morphemes with specific phonological processes directly. They locate at least some idiosyncratic phonology outside of the underlying representation of the morpheme itself. SPE (Chomsky \& Halle 1968) allows for indexing phonological rules to particular morphemes. Indexed Constraint Theory (Benua 1997, Ito \& Mester 1999, Pater 2009) and Transderivational Anti-Faithfulness (Alderete 1999, 2001) allow for morphologically indexed phonological constraints. Cophonology Theory (Orgun 1996, Anttila 1997, Inkelas et al. 1997, Inkelas 1998, Inkelas \& Zoll 2007) allows for the constraint ranking to vary with the morphological construction. Cophonologies by Phase (Sande 2019, Sande et al. 2020) allow for the constraint ranking to vary with the phase and the morphosyntactic features introduced therein.

In this paper, I describe and analyse morphologically determined stress assignment in A'ingae, a language isolate of the Amazon. A'ingae allows for contrastive stress specification on verbal roots (1a) as well as functional morphemes (1b), both of which may result in minimal pairs. Phonetically, stress correlates most robustly with duration and pitch (Repetti-Ludlow et al. 2019). ${ }^{1}$
(1) a. 'nepi -je 'to disappear' disappear-INF
b. 'afa -je 'to speak' speak-INF

\author{
ne'pi -je 'to arrive' \\ arrive-INF \\ a'fa -je 'was spoken' \\ speak-PASS
}

1 The following abbreviations are used, in addition to those in the Leipzig glossing rules: $\mathrm{ADD}=$ additive, $\mathrm{AND}=$ andative, $\mathrm{APPR}=$ apprehensional, $\mathrm{CNTR}=$ contrastive topic, $\mathrm{DS}=$ different subject, $\mathrm{FRST}=$ frustrative, IMP2 $=$ imperative 2 , IMP $3=$ imperative $3, \mathrm{LVL}=$ level attribute, $\mathrm{NEW}=$ new topic, $\mathrm{PAUC}=$ verbal paucal, $\mathrm{PHON}=$ form attribute, $\mathrm{PLS}=$ plural subject, $\mathrm{PRCM}=$ precumulative, $\mathrm{RPRT}=$ reportative, $\mathrm{SEM}=$ meaning attribute, $\mathrm{SMFC}=$ semelfactive, $\mathrm{SS}=$ same subject, THUS = manner demonstrative, $\mathrm{VEN}=$ venitive, $\mathrm{VER}=$ veridical, $\mathrm{YNQ}=$ polar interrogative. 
I propose that A'ingae verbs form two stress classes, stressed and stressless, and that A'ingae functional morphemes form four stress classes, which can be reduced to two binary parameters. The first parameter distinguishes between stressless and prestressing suffixes, and the second distinguishes between stress-preserving (recessive) and stress-deleting (dominant) suffixes. The two parameters vary independently. Typologically similar accentual systems can be found in Japanese (Kawahara 2015) and North-West Caucasian (e.g. Abkhaz; Vaux 2008), as well as Slavic, Baltic, Greek and Sanskrit (for a review, see Kiparsky 2010).

I formalise my analysis of A'ingae verbal stress in Cophonology Theory (e.g. Orgun 1996, Anttila 1997), which captures morpheme-specific phonology with constraint rankings particularised to morphological constructions. I argue that while non-representational approaches such as Cophonology Theory can handle the facts of A'ingae stress deletion straightforwardly, strictly representational approaches (e.g. Trommer \& Zimmermann 2014, Smolensky \& Goldrick 2016, Kushnir 2019, Jaker \& Kiparsky 2020) lack the expressive power necessary to capture the A'ingae facts without abandoning foundational assumptions about the properties of metrical structure (Hayes 1995).

The rest of the paper is structured as follows. $\$ 2$ gives background on the language, including sociolinguistic context and previous scholarship. $\$ 3$ presents the data, motivating the analysis of A'ingae verbs as forming two stress classes and suffixes as forming four stress classes. $\S 4$ formalises the analysis in Cophonology Theory. $\S 5$ argues that purely representational analyses cannot account for the A'ingae stress data.

\section{Background}

A'ingae (also known as Cofán; iso 639-3: con) is an Amazonian language isolate. The language is agglutinating and heavily suffixing. ${ }^{2}$ Verbal morphology is complex, and encodes a large number of semantic categories, including valency, aspect, associated motion, subject features, reality and polarity, illustrated in (2). ${ }^{3}$ The ordering of functional morphemes is given in $\$ 3$.

2 Categorising many of the functional morphemes as suffixes or enclitics is a thorny analytical issue. The glossing used in this paper (with hyphens for suffixes and equals signs for enclitics) primarily reflects Zwicky \& Pullum's (1983) criterion of host selection. As no correlation has been found between the suffixhood or clitichood of A'ingae functional morphemes and stress, this distinction is not essential for the present study. For differing views on the syntactic status of A'ingae functional morphemes, see Dąbkowski (2019) and Fischer \& Hengeveld (in press).

3 Subject person features $(/=\mathrm{ngi} /(1), /=\mathrm{ki} /(2), /=\mathrm{ts} \mathbf{i} /(3))$, polar interrogatives $(/=\mathrm{ti} /$ (YNQ)) and reportative evidentiality (/=te/ (RPRT)) are expressed with second-position clitics. However, when these clitics attach to verbs, their morphophonology patterns with regular suffixes. Thus they are included within the scope of the present study. For a syntactic analysis of A'ingae second-position clitics, see Dąbkowski (2021c). 


\section{Maksymilian Dabkowski}

(2) ko'fi-ã -Phe -ngi -Pfa-ja -mbi =tsi

play-CAUS-IPFV-VEN-PLS-IRR-NEG $=3$

'they will not come to be making play'

A'ingae syllable structure is $(\mathrm{C}) \mathrm{V}(\mathrm{V})(\mathrm{P}) .{ }^{4}$ For the complete phonemic inventory, see Repetti-Ludlow et al. (2019). ${ }^{5}$ The language shows limited regressive and robust progressive nasal spreading. Vowel nasality which results from phonologically predictable spreading is not transcribed; consonant nasality and prenasalisation are. For more on A'ingae nasality, see Sanker \& AnderBois (2021).

All the data come from the author's unpublished fieldnotes and recordings of elicitation sessions conducted over the past four years with five native speakers from the two indigenous communities of Zábalo and Dureno in Sucumbíos, Ecuador.

\subsection{Sociolinguistic context}

A'ingae is an endangered and severely underdocumented language isolate spoken by around 1500 Cofán people. The origin of the Cofán can be traced to the Andes, where they used to range over a large territory. They currently inhabit the province of Sucumbíos in northeast Ecuador and the department of Putumayo in southern Colombia (Repetti-Ludlow et al. 2019). The national borders coincide with a dialectal divide. The data provided in this paper represent the Ecuadorian variety.

Residing at the foot of the Andes, the modern-day Cofán live in one of the most linguistically diverse regions of the world. Previous claims about A'ingae's genealogical relation to other languages, driven mostly by geography, have not been verified; A'ingae is a language isolate. The lexicon of the language has been influenced primarily by the Kichwa, with whom the Cofán have been in contact at least since the late nineteenth century. Other influences include borrowings and wanderwörter from Siona-Secoya, Spanish and Cariban (Dąbkowski 2021a).

${ }^{4}$ Within a narrow morphosyntactic domain, A'ingae glottalisation is licensed by the metrical foot node. The interaction of stress and glottalisation is outside of the scope of this study, and only forms in which glottalisation does not crucially affect stress placement will be considered. For more details, see Dąbkowski (2019, $2021 \mathrm{~b}$, in press).

5 The analysis presented in this paper deviates from the inventory proposed by Repetti-Ludlow et al. (2019) in that it includes/ia/ (and its nasal counterpart/rãa/) among the language's diphthongs. Repetti-Ludlow et al. (2019) claim that /ia/ is realised with an intervening glide [ija], and posit optional deletion of the preconsonantal vowel, resulting in tautosyllabic [ja]. Here, /ia/ is included among the diphthongs because it patterns with them for purposes of stress assignment. For example, the stress shift from ['man dĩa] 'chase' to [ma'ndĩa-mbi] 'chase-NEG' is predicted if ['man $\left.{ }^{\mathrm{n}} \tilde{\mathrm{i}} \tilde{\mathrm{a}}\right]$ is disyllabic, but unexpected if it is trisyllabic. 
In Ecuador, A'ingae is learned by children, and spoken robustly in all domains of life. A majority of the Cofán also speak Spanish, and almost all of them understand it to some degree. The Cofán are predominantly endogamous; some intermarriage with the Kichwa people is reported. In both Ecuador and Colombia, the Cofán and their language face severe pressures from governmental abuse and environmental degradation caused by poaching and illegal oil extraction. There is little institutional support for the language outside of traditional communities. Despite the challenges, the Cofán people's attitudes towards A'ingae are uniformly positive. They take pride in their language, and actively support projects aimed at bolstering its status (Dąbkowski 2021a).

\subsection{Previous scholarship}

Notable contributions to the systematic study of A'ingae include a short dictionary by Borman (1976), a collection of traditional stories by Blaser \& Chica Umenda (2008), a grammar sketch by Fischer \& Hengeveld (in press), a phonetic study by Repetti-Ludlow et al. (2019) and an analysis of the apprehensional domain by AnderBois \& Dąbkowski (2020) and Dąbkowski \& AnderBois (2021, in press).

There have been few treatments of the language's morphology. A short discussion of verbal morphology appears in Borman (1976). Fischer \& Hengeveld (in press) provide the first morphological template to pay attention to the ordering and co-occurrence restrictions among functional morphemes.

Borman (1962), Repetti-Ludlow et al. (2019) and Fischer \& Hengeveld (in press) provide phonetic and phonological descriptions of the language, but touch only marginally on stress. Previous literature does not make systematic attempts to understand the interactions between morphology and phonology. Some of the data and versions of the analysis advanced here appear in Dąbkowski (2019, 2021b, in press).

\section{Verbal stress}

By default, A'ingae primary stress is assigned to the penultimate syllable of the word. Nevertheless, it is often the case that the position of stress cannot be computed on the basis of surface properties alone, and instead requires reference to the morphological composition of the word. In this section, I introduce two stress classes of A'ingae verbs, describe stress assignment as conditioned by four classes of verbal suffixes and present the A'ingae morphological template.

There are two classes of verbal roots in A'ingae: underlyingly stressless and underlyingly stressed. (Underlying stress is always wordinitial.) The membership of a verb in either class is unpredictable. Underlyingly stressless verbs are assigned default penultimate stress 


\section{Maksymilian Dabkowski}

( $3 \mathrm{a}, \mathrm{b})$. Underlying word-initial stress is preserved in surface forms $(3 \mathrm{c}, \mathrm{d})$. I assume that primary stress is the phonetic manifestation of a head trochaic foot, represented in (3) with parentheses. Since the analysis of the morphologically conditioned stress patterns does not rely crucially on the underlying metrical structure, it will not be shown in later examples.

(3)
a. $/ \mathrm{pa}^{\mathrm{n}} \mathrm{dza} / \quad\left[\left(\mathrm{pa}^{\mathrm{n}} \mathrm{dza}\right)\right]$ hunt
Underlyingly stressless verb
b. /atapa/ [a('tapa) $]$ breed

\author{
Underlyingly stressed verb \\ c. /('afa)/ [('afa) $]$ \\ speak \\ d. $/\left({ }^{\prime} \mathrm{ko}^{\mathrm{n}} \mathrm{da}\right) \mathrm{se} / \quad\left[\left({ }^{\prime} \mathrm{ko}^{\mathrm{n}} \mathrm{da}\right) \mathrm{se}\right]$ \\ tell
}

Observe that both (3a) and (3c) have surface penultimate stress. Nevertheless, their underlying representations differ - (3a) is underlyingly stressless, whereas the stress of (3c) is specified at the underlying level. The difference between (3a) and (3c) is revealed, for example, in forms suffixed with the precumulative suffix /-hi/, which forms part of the phonological word, but does not affect preexisting stress. In (4a), penultimate stress is supplied by default. In (4b), the underlying word-initial stress is preserved.

(4) $V e r b+/-h i /($ PRCM)
a. stressless
/pandza -hi/
$\left[\mathrm{pa}^{\mathrm{n} n \mathrm{dza}} \mathrm{hi}\right]$
hunt -PRCM
/atapa -hi/
[ata'pa-hi]
breed-PRCM
b. stressed

/'afa -hi/
['afa -hi]
speak-PRCM
/'kondase-hi/
['kon dase-hi]
tell -PRCM

The precumulative /-hi/ represents the first of A'ingae's four suffix classes: RECESSIVE STRESSLESS. Recessive stressless suffixes do not contribute their own stress (hence stressless) and do not affect preexisting stress (hence recessive). However, they form a part of the phonological word, so they count for purposes of default penultimate stress assignment (4a). Recessive stressless suffixes are represented without subscripts or superscripts.

The only other recessive stressless suffix is the causative, realised as /-na/ on monosyllables (5a), as /-ẽ/ on polysyllables ending in $/ \mathrm{a} /$ or $/ \mathrm{o} /(5 \mathrm{~b})$ and as $/-\tilde{a} /$ on polysyllables ending in $/ \mathrm{e} /, \mid \mathrm{i} /$ or $/ \mathbf{i} /(5 \mathrm{c}, \mathrm{d})$. The allomorphs $/-\tilde{\mathrm{e}} /$ and $/-\tilde{a} /$ do not form separate syllables, but rather diphthongs with the preceding vowel, which is reflected in the assignment of the default penultimate stress $(5 \mathrm{a}-\mathrm{c})$. Preexisting stress, when present, is preserved $(5 \mathrm{~d})$. Syllable boundaries are shown with a dot. Note that hyphens represent morpheme boundaries, not syllable boundaries. 
(5) $V e r b+/-$ na/ (cAus)
a. /phi. -na/
['phi.-na]
sit -CAUS
b. /pa. ${ }^{\mathrm{n}} \mathrm{d} z \mathrm{a}-\tilde{\mathrm{e}} /$
['pa. $\left.{ }^{\mathrm{n}} \mathrm{dza}-\tilde{1}\right]$
hunt -CAUS
c. /a.fe $-\tilde{a} /$
['a.fi -ã]
give-CAUs
d. /'ko. ${ }^{\mathrm{n}}$ da.se-ã/
['ko. $\left.{ }^{\mathrm{n}} \mathrm{da} . \mathrm{si}-\tilde{a}\right]$
tell
-CAUS

When both suffixes are present, causative /-na/ precedes precumulative /-hi/. Stress falls on the penultimate syllable (6a) unless blocked by preexisting stress $(6 \mathrm{~b})$.

(6) $V e r b+/$-na/ (CAUs) $+/$-hi/ (PRCM)
a. stressless

$$
\begin{aligned}
& \text { /phi-na -hi/ } \\
& \text { [phi-'na -hi] } \\
& \text { sit -CAUS-PRCM }
\end{aligned}
$$
$/ \mathrm{pa}^{\mathrm{n}} \mathrm{dza}-\tilde{\mathrm{e}} \quad-\mathrm{hi} /$
$\left[\mathrm{pa}^{\ln \mathrm{d} z \mathrm{a}-\tilde{\mathrm{i}}}-\mathrm{hi}\right]$
b. stressed

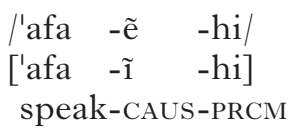
hunt -CAUS-PRCM
/'kondase-ã -hi/
['kon dasi -ã -hi]
tell -CAUS-PRCM

The second suffix class comprises DOMINANT STRESSLESS suffixes. Dominant stressless suffixes do not contribute their own stress (hence stressless), and delete preexisting stress if any is present (hence dominant; see Halle \& Vergnaud 1987, Inkelas 1998, Alderete 1999, Revithiadou 1999, Vaxman 2016, Rolle 2018). If there is no preexisting stress, dominant stressless suffixes have no effect. That is to say, dominant stressless suffixes, represented here with ${ }^{\varnothing}$, turn stressed verbs into stressless ones. There are three dominant stressless suffixes: reciprocal $/-\mathrm{kho}^{\varnothing} /$, passive $/-\mathrm{je}^{\varnothing} /$ and the verbal paucal $/-\mathrm{k}^{\mathrm{h}} \mathrm{a}^{\varnothing} / .^{6}$

When a dominant stressless suffix attaches to a stressless verb, the surface form shows the default penultimate stress (7a). However, when it attaches to a stressed verb, the verb's stress is deleted, feeding the assignment of the default penultimate stress even to underlyingly stressed $\operatorname{verbs}(7 b)$.

(7) $V e r b+/-\mathrm{k}^{\mathrm{h}} \mathrm{O}^{\varnothing} /(\mathrm{RECP})$
a. stressless
$\left|\mathrm{pa}^{\mathrm{n}} \mathrm{dza}-\mathrm{k}^{\mathrm{h}} \mathrm{o}^{\varnothing}\right|$
$\left[\mathrm{pa}^{\mathrm{in}} \mathrm{dza}-\mathrm{k}^{\mathrm{h}} \mathrm{O}\right]$
|atapa $-\mathrm{k}^{\mathrm{h}} \mathrm{O}^{\varnothing}$
[ata'pa-k $\mathrm{h}^{\mathrm{O}}$ ]
hunt -RECP
breed-RECP

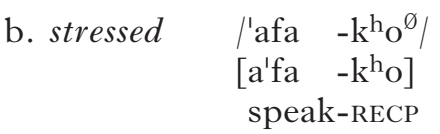
/'kon dase- $\mathrm{k}^{\mathrm{h}} \mathrm{O}^{\varnothing} /$
$\left[\mathrm{ko}^{\mathrm{n}} \mathrm{da}^{\prime} \mathrm{se}-\mathrm{k}^{\mathrm{h}} \mathrm{o}\right]$
tell -RECP

A dominant stressless suffix may delete preexisting stress across another suffix (8a), and may itself be stressed if followed by another stressless

${ }^{6}$ I do not discuss the stress pattern with the preglottalised dominant stressless suffixes /-Phe/ (IPFV), - / nak $^{\mathrm{h}} \mathrm{a} /$ (SMFC), /-Pngi/ (VEN) and /-Pnga/ (AND), but they are included in Table II for completeness. For a discussion of these suffixes and the interaction between glottalisation and stress more generally, see Dąbkowski $(2019,2021 \mathrm{~b}$, in press). 


\section{Maksymilian Dabkowski}

suffix (8b). A sequence of dominant stressless suffixes has the same stress deletion properties as one dominant stressless suffix (8c). In all these situations, after the verb's stress is deleted, penultimate stress is assigned by default.

\begin{tabular}{|c|c|c|}
\hline \multicolumn{3}{|c|}{ 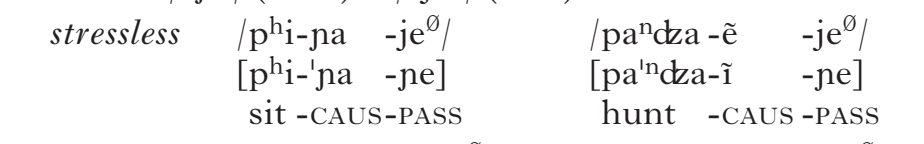 } \\
\hline stressed & $\left.\begin{array}{lll}\text { /'afa } & -\tilde{e} & -\mathrm{je}^{\varnothing} / \\
{\left[\mathrm{a}^{\prime} \mathrm{fa}\right.} & -\tilde{\mathrm{i}} & -\mathrm{ne}\end{array}\right]$ & $\begin{array}{ll}/ \text { 'ko }^{\mathrm{n}} \text { dase-ã } & -\mathrm{je}^{\varnothing} / \\
{\left[\mathrm{ko}^{\mathrm{n}} \mathrm{da}{ }^{\prime} \mathrm{si} \text {-ã }\right.} & -\mathrm{ne}]\end{array}$ \\
\hline & speak-CAUS-PASS & tell -CAUS-PASS \\
\hline $\begin{array}{l}\text { Verb }+1-\text { - } \\
\text { stressless }\end{array}$ & 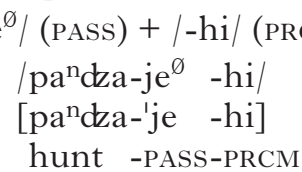 & 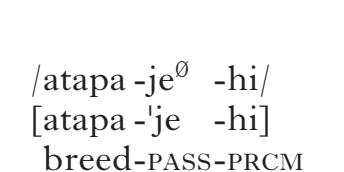 \\
\hline stressed & 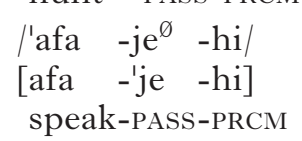 & 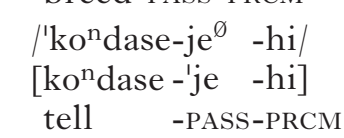 \\
\hline $\begin{array}{l}\text { Verb }+/- \\
\text { stressless }\end{array}$ & $\begin{array}{l}{ }^{\mathrm{n}} \mathrm{O}^{\varnothing} /(\mathrm{RECP})+/-\mathrm{je}^{\varnothing} /( \\
/ \text { afe }-\mathrm{k}^{\mathrm{h}} \mathrm{O}^{\varnothing}-\mathrm{je} \mathrm{e}^{\varnothing} / \\
{\left[\text { afe }-\mathrm{k}^{\mathrm{h}} \mathrm{O}-\mathrm{je}\right]} \\
\text { give-RECP-PASS }\end{array}$ & $\begin{array}{l}\text { S) } \\
\text { /atapa }-\mathrm{k}^{\mathrm{h}} \mathrm{O}^{\varnothing}-\mathrm{je} \mathrm{e}^{\varnothing} / \\
{\left[\text { atapa }-\mathrm{k}^{\mathrm{h}} \mathrm{O}-\mathrm{je}\right]} \\
\text { breed-RECP-PASS }\end{array}$ \\
\hline stressed & $\begin{array}{ll}\text { /'afa } & -\mathrm{k}^{\mathrm{h}} \mathrm{O}^{\varnothing}-\mathrm{j} \mathrm{e}^{\varnothing} / \\
{\left[\begin{array}{ll}\text { afa } & -\mathrm{k}^{\mathrm{h}} \mathrm{O}-\mathrm{je}\end{array}\right]}\end{array}$ & $\begin{array}{l}/ \mathrm{ko}^{\mathrm{n}} \text { dase }-\mathrm{k}^{\mathrm{h}} \mathrm{o}^{\emptyset}-\mathrm{je} \mathrm{e}^{\emptyset} \\
{\left[\mathrm{ko}^{\mathrm{n}} \text { dase - } \mathrm{k}^{\mathrm{h}} \mathrm{O}-\mathrm{je}\right]}\end{array}$ \\
\hline & speak-RECP- & $-\mathrm{RECP}-$ \\
\hline
\end{tabular}

The third suffix class comprises RECESSIVE PRESTRESSING suffixes. Recessive prestressing suffixes place stress on the immediately preceding syllable (hence prestressing), but only if there is no preexisting stress (hence recessive). The recessive prestressing suffixes are represented with $\_$. They are by far the most numerous class, including the plural subject $\left|-P \mathrm{fa}_{\leftarrow}\right|$, irrealis $\left|-\mathrm{ja}_{\leftarrow}\right|$, negative $\left|-\mathrm{mbi}_{\leftarrow}\right|$, imperative $\mid-$ ha $\mathrm{s}_{\leftarrow} \mid$ and apprehensional /-sa?ne $/$. Prestressing suffixes, both dominant and recessive, linearly follow stressless suffixes. Due to the morphological organisation of the verb, a stressless suffix never occurs to the right of a prestressing suffix.

When one monosyllabic prestressing suffix is present on a stressless verb, stress is assigned to the last syllable of the root, resulting in penultimate stress (9a.i). The stress of underlyingly stressed verbs is not affected (9a.ii). In consequence, the output forms with one monosyllabic prestressing suffix are indistinguishable from those with a recessive stressless suffix in (4). However, when the prestressing suffix is disyllabic, prestressing results in antepenultimate stress, rather than penultimate stress (9b). 
(9) a. Verb $+/-\mathrm{ja}_{\leftarrow} /($ IRR $)$

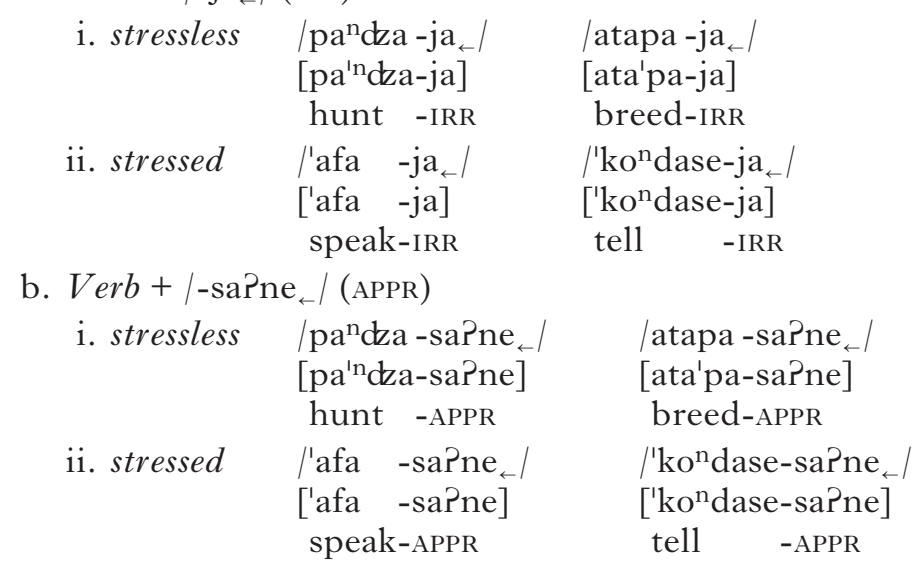

The behaviour of recessive stressless suffixes and recessive prestressing suffixes also differs when more than one prestressing suffix is present. The first prestressing suffix assigns stress to the syllable which immediately precedes it (if there is no preexisting stress). The following recessive prestressing suffixes respect preexisting stress, including that assigned by an earlier suffix, so they do not shift stress. Thus, in forms with multiple prestressing suffixes, the output stress is root-final on underlyingly stressless verbs (10a) and word-initial on underlyingly stressed verbs (10b).

$$
\begin{aligned}
& V e r b+/-P \mathrm{fa}_{\leftarrow} /(\mathrm{PLS})+/-\mathrm{ja} \mathrm{a}_{\leftarrow} /(\mathrm{IRR}) \\
& \text { a. stressless } \quad / \mathrm{pa}^{\mathrm{n}} \mathrm{cza}-\mathrm{Pfa}_{\leftarrow}-\mathrm{ja} \mathrm{j}_{\leftarrow} \mid \\
& {[\text { pa'ndza-Pfa }- \text { ja] [ata'pa-Pfa }- \text { ja] }} \\
& \text { hunt -PLS -IRR breed-PLS -IRR } \\
& \text { b. stressed } \quad \text { /'afa } \quad-2 \mathrm{fa}_{\leftarrow}-\mathrm{ja} \mathrm{a}_{\leftarrow} / \\
& {\left[\begin{array}{lll}
\text { 'afa } & -\mathrm{Pfa} & -\mathrm{ja}
\end{array}\right]} \\
& \text { speak-PLS -IRR } \\
& \text { /'kondase-Pfa }{ }_{\leftarrow}-\mathrm{ja}_{\leftarrow} / \\
& \text { ['kon dase-Pfa }-\mathrm{ja}] \\
& \text { tell } \quad \text {-PLS }- \text { IRR }
\end{aligned}
$$

When both recessive stressless and recessive prestressing suffixes are present on a stressless verb, stress falls immediately before the first prestressing suffix (11a). The stress of underlyingly stressed verbs remains unaffected (11b).

(11) a. Stressless verb + recessive stressless + recessive prestressing suffixes

$$
\begin{aligned}
& / \mathrm{p}^{\mathrm{h}} \mathrm{i}-\mathrm{hi} \quad-\mathrm{Pfa}_{\leftarrow} / \quad / \mathrm{p}^{\mathrm{h}} \mathrm{i}-\mathrm{na} \quad-\mathrm{hi} \quad-\mathrm{Pfa}_{\leftarrow}-\mathrm{ja}_{\leftarrow}-\mathrm{mbi}_{\leftarrow}=\mathrm{ti} \mathrm{i}_{\leftarrow}=\mathrm{ki}_{\leftarrow} /
\end{aligned}
$$

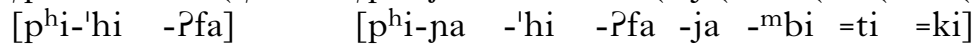

$$
\begin{aligned}
& \text { sit -PRCM-PLS sit -CAUS-PRCM-PLS -IRR -NEG }=\mathrm{YNQ}=2
\end{aligned}
$$

b. Stressed verb + recessive stressless + recessive prestressing suffixes
/'afa -hi
$-2 \mathrm{fa}_{\leftarrow} /$
/'afa -ẽ
-hi
$-2 \mathrm{fa}_{\leftarrow}-\mathrm{ja} \mathrm{a}_{\leftarrow}-\mathrm{mbi}_{\leftarrow}=\mathrm{ti} \mathrm{i}_{\leftarrow}=\mathrm{ki} \mathrm{i}_{\leftarrow}$ ['afa - hi - -Pfa] $[$ 'afa $-\tilde{1}$
-hi $\quad-P f a \quad-j a \quad-m b i=t i \quad=k i]$ speak-PRCM-PLS speak-CAUS-PRCM-PLS - IRR $-\mathrm{NEG}=\mathrm{YNQ}=2$ 


\section{Maksymilian Dabkowski}

Dominant stressless suffixes delete preexisting stress, feeding the recessive prestressing suffixes, which assign stress only if no preexisting stress is present. Consequently, when a stressed verb is followed by at least one dominant stressless suffix and at least one prestressing suffix, stress falls immediately to the left of the first prestressing suffix (12), like the stressless verbs in (11a).

$$
\begin{aligned}
& \text { Stressed verb }+ \text { dominant stressless }+ \text { recessive prestressing } \\
& \text { /'afa }-\mathrm{je}^{\varnothing}-\mathrm{Pfa} \mathrm{a}_{\leftarrow} / \quad \text { /'afa } \quad-\mathrm{k}^{\mathrm{h}} \mathrm{O}^{\varnothing}-\mathrm{je}^{\varnothing}-\mathrm{Pfa}_{\leftarrow}-\mathrm{ja} \mathrm{a}_{\leftarrow}-\mathrm{mbi}_{\leftarrow}=\mathrm{ti} \mathrm{i}_{\leftarrow}=\mathrm{ki} \mathrm{i}_{\leftarrow} /
\end{aligned}
$$

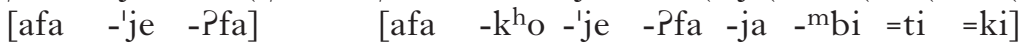

$$
\begin{aligned}
& \text { speak-PASS-PLS speak-RECP-PASS-PLS }- \text { IRR -NEG }=\text { YNQ }=2
\end{aligned}
$$

Stressless suffixes, both dominant and recessive, always precede the prestressing ones. Therefore, the suffix orders discussed above are the only ones attested.

The final suffix class comprises DOMINANT PRESTRESSING suffixes. Dominant prestressing suffixes delete preexisting stress (hence dominant) and place stress on the immediately preceding syllable (hence prestressing). Thus the prestressing associated with these suffixes completely replaces preexisting stress, if any was present. The dominant prestressing suffixes are represented with $\underset{\leftarrow}{\varnothing}$. There are two dominant prestressing suffixes: the 2 nd person imperative $/-\mathrm{k}^{\mathrm{h}} \mathrm{a}_{\leftarrow}^{\varnothing} /$ and the prohibitive $/$-hama ${ }_{\leftarrow}^{\varnothing} /$. The dominant prestressing suffixes follow stressless suffixes. Thus a stressless suffix never occurs to the right of a prestressing suffix. However, a dominant prestressing suffix may be followed by a recessive prestressing one.

When a dominant prestressing suffix attaches to a stressless verb, stress is assigned to the last syllable of the root (13a.i, b.i). When a dominant prestressing suffix attaches to a stressed verb, the verb's stress is deleted and stress is also assigned to the last syllable of the root (13a.ii, b.ii).

\begin{tabular}{|c|c|c|}
\hline \multicolumn{3}{|c|}{ a. $V e r b+/-\mathrm{k}^{\mathrm{h}} \mathrm{a}_{\leftarrow}^{\varnothing} /($ IMP 2$)$} \\
\hline i. stressless & $\begin{array}{l}\mid \mathrm{pa}^{\mathrm{n}} \mathrm{dza}-\mathrm{k}^{\mathrm{h}} \mathrm{a}_{\leftarrow}{ }_{\leftarrow} / \\
{\left[\mathrm{pa} \mathrm{a}^{\mathrm{n}} \mathrm{n} \mathrm{dz}-\mathrm{k}^{\mathrm{h}} \mathrm{a}\right]}\end{array}$ & \\
\hline ii. stressed & $\begin{array}{l}\text { hunt }- \text { IMP2 } \\
\text { /'ana }-\mathrm{k}^{\mathrm{h}} \mathrm{a}_{\leftarrow}^{\varnothing} / \\
\left.\text { [a'na }-\mathrm{k}^{\mathrm{h}} \mathrm{a}\right] \\
\text { sleep-IMP2 }\end{array}$ & $\begin{array}{l}\mid ' \mathrm{kati}^{\mathrm{h}} \mathrm{h}_{\mathrm{a}} \oslash \\
{\left[\mathrm{ka} \text { 'ti-k } \mathrm{k}^{\mathrm{h}} \mathrm{a}\right]} \\
\text { cast-IMP2 }\end{array}$ \\
\hline \multicolumn{3}{|c|}{ b. Verb $+/$-hama } \\
\hline i. stressless & $\begin{array}{l}\text { /pandza -hama }{ }_{\leftarrow}^{\varnothing} / \\
{\left[\mathrm{pa}^{\ln } \mathrm{dza}-\text { hama }\right]} \\
\text { hunt -PROH }\end{array}$ & $\begin{array}{c}\text { /atapa -hama } \\
{[\text { ata'pa-hama] }} \\
\text { breed-PROH }\end{array}$ \\
\hline ii. stressed & $\begin{array}{ll}\text { /'afa } & - \text { hama } \\
\text { [a'fa } & \text {-hama] }\end{array}$ & $\begin{array}{l}\text { /'kondase-hama }{ }_{\leftarrow}^{\varnothing} / \\
{\left[\mathrm{ko}^{\mathrm{n}} \text { da'se-hama }\right]}\end{array}$ \\
\hline & speak-PROH & $-\mathrm{PROH}$ \\
\hline
\end{tabular}


When additional suffixes intervene between a stressless verb and the dominant prestressing suffix, stress is always assigned to the syllable immediately preceding the dominant prestressing suffix, regardless of whether the intervening suffixes are recessive stressless (14a), dominant stressless (14b), recessive prestressing (14c) or any combination of the three $(14 d-f)$.

$$
\begin{aligned}
& \text { Stressless verb }+\ldots+/ \text {-hama }
\end{aligned}
$$

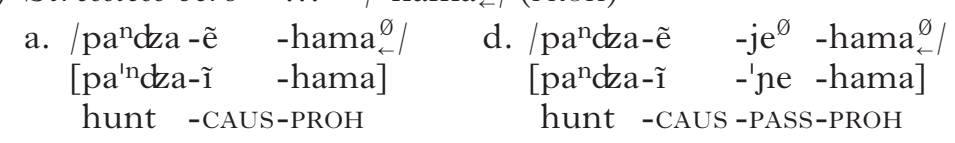

$$
\begin{aligned}
& \text { b. } / \text { pa }^{\mathrm{n}} \mathrm{cza}-\mathrm{je} \mathrm{e}^{\varnothing}-\mathrm{hama}_{\leftarrow}^{\varnothing} / \\
& {\left[\mathrm{pa}^{\mathrm{n}} \mathrm{dza}-\mathrm{-}^{\mathrm{j} j}\right. \text {-hama] }} \\
& \text { hunt -PASS-PROH } \\
& \text { c. /pandza-Pfa }{ }_{\leftarrow}-\text { hama }{ }_{\leftarrow}^{\varnothing} / \\
& \text { [pandza-P'fa -hama] } \\
& \text { hunt -PLS -PROH }
\end{aligned}
$$
e. $/ \mathrm{pa}^{\mathrm{n}} \mathrm{dza}$-e $\quad-P f a_{\leftarrow}-h a m a_{\leftarrow}^{\varnothing} /$$$
\left[\mathrm{pa}^{\mathrm{n}} \mathrm{d} \mathrm{k} \mathrm{a}-\tilde{\mathrm{I}} \quad-\mathrm{P}^{\prime} \mathrm{fa}-\text {-hama}\right]
$$$$
\text { hunt -CAUS-PLS -PROH }
$$$$
\text { f. } / \text { pa }^{\mathrm{n}} \mathrm{dza}-\mathrm{k}^{\mathrm{h}} \mathrm{O}^{\varnothing}-\mathrm{Pfa}_{\leftarrow}-\mathrm{hama}_{\leftarrow}^{\varnothing} /
$$$$
\left[\mathrm{pa}^{\mathrm{n}} \mathrm{dza}-\mathrm{k}^{\mathrm{h}} \mathrm{O}-\mathrm{P} \text { 'fa }-\right. \text { hama] }
$$$$
\text { hunt -RECP-PLS -PROH }
$$

The same generalisation holds when the verbal root is stressed (15).

$$
\begin{aligned}
& \text { a. Stressed verb }+\ldots+/ \text {-hama }
\end{aligned}
$$

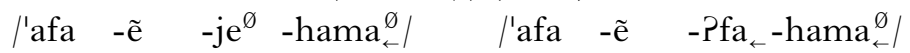

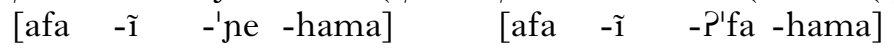

$$
\begin{aligned}
& \text { speak-CAUS-PASS-PROH speak-CAUS-PLS -PROH }
\end{aligned}
$$

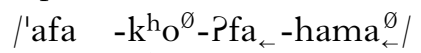

$$
\begin{aligned}
& \text { [afa }-\mathrm{k}^{\mathrm{h}} \mathrm{O}-\mathrm{P}^{\prime} \mathrm{fa} \text {-hama] } \\
& \text { speak-RECP-PLS -PROH } \\
& \text { b. Stressed verb }+/-\mathrm{Pfa}_{\leftarrow} / \text { (PLS) }+/-\mathrm{k}^{\mathrm{h}} \mathrm{a}_{\leftarrow}^{\varnothing} / \text { (IMP2) }
\end{aligned}
$$

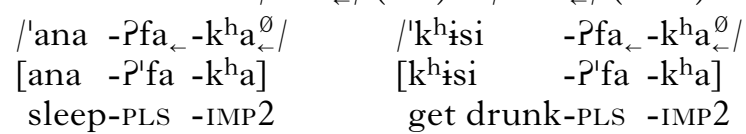

A dominant prestressing suffix can be followed by recessive prestressing suffixes. Since recessive prestressing suffixes do not alter preexisting stress, the stress assigned by the dominant prestressing suffix is preserved (16). ${ }^{7}$ 
(16) Verb $+/$-hama

a. stressless $\quad\left|\mathrm{pa}^{\mathrm{n}} \mathrm{dza}-\mathrm{hama} \mathrm{q}_{\leftarrow}^{\emptyset}=\mathrm{te}_{\leftarrow}=\mathrm{ke}_{\leftarrow}\right|$

$\left[\mathrm{pa}^{\text {'n }} \mathrm{dza}\right.$-hama $\left.={ }^{\mathrm{n}} \mathrm{de}=\mathrm{ke}\right]$

hunt $-\mathrm{PROH}=\mathrm{RPRT}=$ ?

b. stressed /'afa $\quad-$ hama $_{\leftarrow}^{\varnothing}=\mathrm{te}_{\leftarrow}=\mathrm{ke}_{\leftarrow} /$

[a'fa - hama $\left.={ }^{\mathrm{n}} \mathrm{de}=\mathrm{ke}\right]$

speak-PROH $=$ RPRT=?

Thus stress surfaces one syllable to the left of the dominant prestressing suffix regardless of which other suffixes come before and after it. The two dominant prestressing suffixes do not co-occur. Furthermore, prestressing suffixes (both recessive and dominant) never occur before stressless suffixes (again irrespective of dominance). As such, the suffix orders discussed above exhaust all of the attested combinations.

The four suffix classes (recessive stressless, dominant stressless, recessive prestressing, dominant prestressing) can be seen as emerging from two independently varying binary morphophonological parameters: prestressing and dominance. All A'ingae suffixes belong to one of the four classes. This is schematised in Table I.

\begin{tabular}{|c|c|c|}
\cline { 2 - 3 } \multicolumn{1}{c|}{} & recessive & dominant \\
\hline stressless & retains preexisting stress & $\begin{array}{c}\text { deletes preexisting stress } \\
\text { always prestresses }\end{array}$ \\
prestressing & prestresses unless stress already exists & \\
\hline
\end{tabular}

Table I

Stress operations of the four suffix classes.

A'ingae's heavily agglutinating suffixation expresses multiple semantic and pragmatic categories, organised in a morphological template with a dozen or so slots. The template is given in Table II. ${ }^{8}$

A'ingae also has secondary stress, which is assigned without reference to the morphological composition of the word and alternates predictably on every other syllable (17a). In forms with an odd number of posttonic syllables, a two-syllable lapse between primary stress and secondary stress arises (17b). Degenerate feet are not constructed (Dąbkowski 2019). Since secondary stress does not affect morphologically conditioned primary stress assignment, I do not transcribe or analyse it in this paper.

(17) Secondary stress
a. ('afa) (-,ja-mbi) (=,ti=ki)
speak $-\mathrm{IRR}-\mathrm{NEG}=\mathrm{YNQ}=2$
b. pa('ndza-Pfa) - ja $\left(-{ }_{1}\right.$ bi bi
hunt $-\mathrm{PLS}-\mathrm{IRR}-\mathrm{NEG}=\mathrm{YNQ}$

8 Some co-occurrence restrictions are found among A'ingae suffixes and clitics. They are orthogonal to this study. For further discussion, see Dąbkowski (2019). 


\begin{tabular}{|c|c|}
\hline $\begin{array}{l}\text { (i) causative } \\
\text { (ii) reciprocal } \\
\text { (iii) passive } \\
\text { (iv) aspect } \\
\text { (v) associated motion } \\
\text { (vi) subject number } \\
\text { (vii) reality } \\
\text { (viii) polarity } \\
\text { (ix) clause type: } \\
\quad \text { subordinate } \\
\quad \text { cosubordinate } \\
\quad \text { matrix } \\
\text { (x) information structure } \\
\text { (xi) sentence-level } \\
\text { (xii) subject person }\end{array}$ & 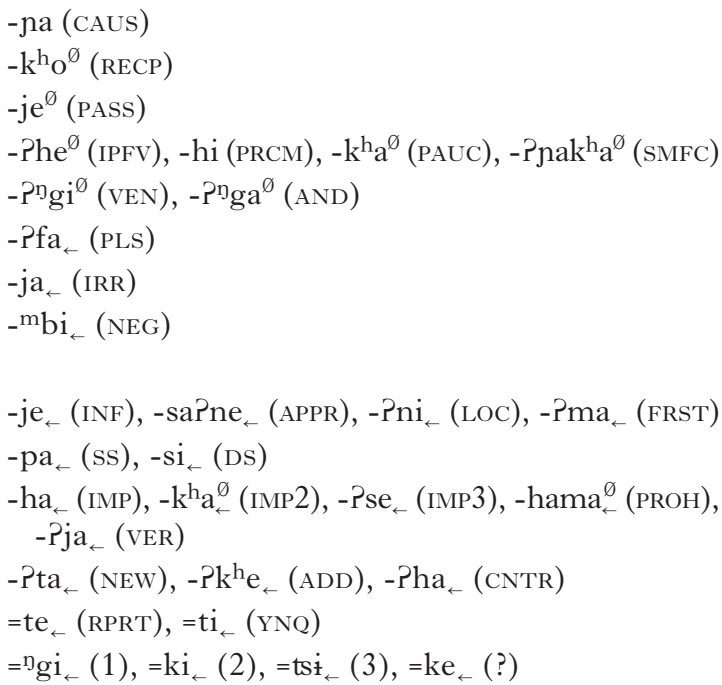 \\
\hline
\end{tabular}

Table II

Inflectional template of the A'ingae verb.

\section{Analysis}

\subsection{Cophonology Theory}

Cophonology Theory (Orgun 1996, Anttila 1997, among others) is a formal framework of the phonology-morphology interface, which particularises aspects of the phonological grammar to morphological constructions. In doing so, it splits the grammar of a language into multiple phonological subgrammars.

Cophonology Theory models morpheme-specific phonology by associating morphological processes with phonological subgrammars, known as cophonologies. The phonological subgrammars are themselves morphologically blind, which predicts that the phonology of a word depends on the phonologies of its constituent parts and their hierarchical organisation (Inkelas \& Zoll 2007, Caballero 2011).

Morphological primitives (such as roots and affixes) and morphologically complex expressions are modelled as signs. Morphological processes are modelled as constructions that combine these signs to yield a new sign. Signs are formalised as attribute-value matrices. Each sign is associated with a syntactic category, as well as a meaning attribute SEMANTICS (SEM) and a form attribute PHONOLOGY (PHON). The value of PHON is a phonological string computed as the output of a constructionspecific phonological function (cophonology) applied to its inputs. The OT constraints which make up cophonologies are general; they themselves 


\section{Maksymilian Dabkowski}

do not refer to morphological categories. When cophonologies differ across morphological constructions, morpheme-specific phonology obtains (Inkelas 1998, Inkelas \& Zoll 2005, Caballero 2011).

An example of an affixation construction in A'ingae is given in Fig. 1, where the form [afaseje] 'offend-PAss' is licensed by the verb/'afase/ 'offend' and the passive suffix /-je/. The two daughters correspond to the input verb and suffix; the mother corresponds to the output. Boxed indices mark those values whose identity is imposed by the construction.

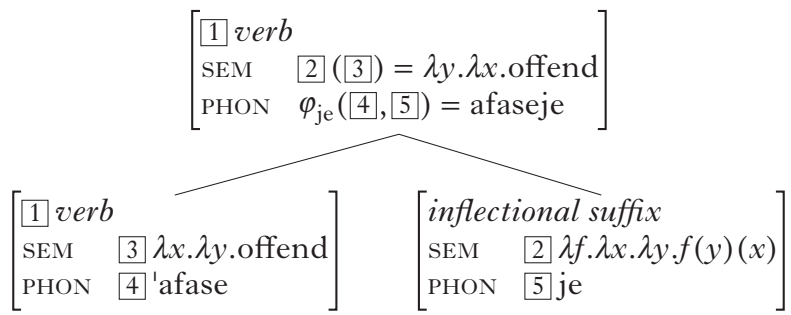

Figure 1

The inflectional construction [afaseje] 'offend-PAss'.

The left daughter's category is a verb, while the right daughter's category is an inflectional suffix. Since the construction is inflectional, the mother node's category is identified with the category of its left daughter. The mother node's semantics is the output of applying the meaning function of $/$-je/ to /'afase/. Finally, its phonology is the output of a construction-specific cophonological function whose two arguments are the phonologies of its two daughters. Stress deletion is found in the mother node's form [afaseje], a consequence of applying the cophonological function associated with the passive suffix /-je/ to /'afase/ and /je/. An analysis of stress deletion will be given in $\$ 4.2$.

The dependence of a word's phonology on the phonologies of its constituent parts and their hierarchical organisation is derived from the very architecture of Cophonology Theory. Since the morphological constructions apply sequentially, complex words have branching structures, as represented in (18) (Inkelas 1998, Inkelas \& Zoll 2007, Caballero 2011), where cophonological functions are represented with $\varphi$.

(18) Morphophonological constituency in Cophonology Theory

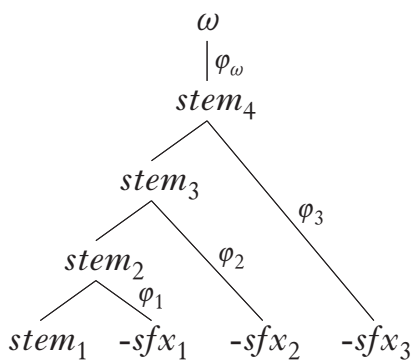


This hierarchical structure has a direct phonological correlate: the phonologies of branching nodes depend exclusively on the phonologies of their daughters. For example, the phonology of the $\omega$ node is the output of the function $\varphi_{3}\left(s t e m_{3},-s f x_{3}\right)$, which is blind to the fact that the stem $_{3}$ node is itself a morphological complex of stem $_{2}$ and $s f x_{2}$. Likewise, the function $\varphi_{2}$ as applied to its two arguments, stem ${ }_{2}$ and $-s f x_{2}$, does not have access to information about $s f x_{3}$ and $\omega$, which come later. In this way, the branching structure of morphologically complex words models 'bracket erasure', deriving the domains of applicability for particular cophonologies (Inkelas \& Zoll 2007, Caballero 2011). Finally, I propose that the last output of a morphological operation $\left(\right.$ here stem $_{4}$ ) may undergo one final phonological evaluation by itself, represented as $\varphi_{\omega}$, which promotes it to the $\omega$ (if stem $_{4}$ is not already prosodified).

In this study, cophonologies are implemented within Optimality Theory, which treats the observed linguistic forms as a consequence of optimal satisfaction of conflicting constraints (McCarthy \& Prince 1993a, b, Prince \& Smolensky 1993). Thus different cophonologies correspond to different constraint rankings.

\subsection{Implementation}

In the Cophonology Theory analysis to be pursued here, the five stress operations seen in $\$ 3$ (four suffix classes plus default penultimate stress assignment) will be associated with five different cophonologies, or different rankings of phonological constraints.

First, recessive stressless suffixes are associated with the RECEssive STRESSLESS cophonology. They preserve preexisting stress and do not themselves assign any stress: if there is input stress, it is preserved. If there is no stress in the input, none is assigned. In other words, when the recessive stressless cophonology applies, outputs are fully faithful to the inputs. This is captured with high-ranking $\operatorname{Max}(\mathrm{Ft})(19 \mathrm{a})$, which favours preservation of the input metrical structure (metrical feet), and $\operatorname{Dep}(\mathrm{Ft})(19 \mathrm{~b})$, which prevents the construction of metrical feet in the output if they are absent in the input.

(19) a. $\operatorname{Max}(\mathrm{Ft})$

For every metrical foot in the input, there is a corresponding metrical foot in the output.

b. $\operatorname{Dep}(\mathrm{Ft})$

For every metrical foot in the output, there is a corresponding metrical foot in the input.

When a recessive stressless suffix attaches to a stressless stem, the output is also stressless (20a). This is because the candidates which add stress incur violations of $\operatorname{DEP}(\mathrm{Ft})$. When a recessive stressless suffix attaches to a stressed stem, that stress is preserved in the output (20b). The candidates 


\section{Maksymilian Dabkowski}

which remove stress incur violations of $\operatorname{MAx}(\mathrm{Ft})$; the candidates which remove input stress and add stress somewhere else incur violations of both $\operatorname{Max}(\mathrm{Ft})$ and $\operatorname{DeP}(\mathrm{Ft}){ }^{9}$ Input stems are given in []$^{10}$

Recessive stressless

a.

\begin{tabular}{|r|c:c|}
\hline \multicolumn{1}{c|}{$\left.\mathrm{pa}^{\mathrm{n}} \mathrm{dza}\right] \mathrm{hi}$} & $\operatorname{Max}(\mathrm{Ft})$ & $\operatorname{DEp}(\mathrm{Ft})$ \\
\hline i. $\mathrm{pa}^{\mathrm{n}} \mathrm{dzahi}$ & & \\
\hline ii. 'pa ${ }^{\mathrm{n}} \mathrm{dzahi}$ & & $* !$ \\
\hline iii. pa ${ }^{\text {'n }} \mathrm{dzahi}$ & & $* !$ \\
\hline iv. pa ${ }^{\mathrm{n}} \mathrm{dza}$ 'hi & & $* !$ \\
\hline
\end{tabular}

b.

\begin{tabular}{|r|c:c|}
\hline ['afa]hi & $\operatorname{MAx}(\mathrm{Ft})$ & $\operatorname{Dep}(\mathrm{Ft})$ \\
\hline i. afahi & $* !$ & \\
\hline ii. 'afahi & & \\
\hline iii. a'fahi & $* !$ & $* !$ \\
\hline iv. afa'hi & $* !$ & $* !$ \\
\hline
\end{tabular}

Note that stress in the output of (20a) is absent, not penultimate (cf. (4a)). The default penultimate stress is assigned later, after all the morphophonological operations.

Second, dominant stressless suffixes are associated with the DOMINANT STREssless cophonology. They delete stress and do not themselves assign any stress. This is captured by ranking *FOOT in (21), which favours outputs without metrical structure, above $\operatorname{MAx}(\mathrm{Ft})$.

(21) *FoOT

There is no metrical structure in the output.

When a dominant stressless suffix attaches to a stressless stem, the output is stressless, as favoured by both *Foot and $\operatorname{DeP}(\mathrm{Ft})$ (22a). When a dominant stressless suffix attaches to a stressed stem, the output is likewise stressless (22b). All the stressed candidates incur violations of *FoOT.

\section{Dominant stressless}

a.

\begin{tabular}{|c|c|c|}
\hline$\left[\mathrm{pa}^{\mathrm{n}} \mathrm{dza}\right] \mathrm{je}^{\varnothing}$ & $\begin{array}{r:c}* \mathrm{FT}_{\mathrm{T}} & \mathrm{DEP} \\
& (\mathrm{Ft})\end{array}$ & $\begin{array}{c}\mathrm{M}_{\mathrm{Ax}} \\
(\mathrm{Ft})\end{array}$ \\
\hline i. $\mathrm{pa}^{\mathrm{n}} \mathrm{dzaje}$ & & \\
\hline ii. 'pandzaje & $* !$ & \\
\hline iii. $\mathrm{pa}^{\mathrm{In}} \mathrm{dzaje}$ & $* !$ & \\
\hline iv. $p a^{n} d z a^{\prime} j e$ & $* !$ & \\
\hline
\end{tabular}

b.

\begin{tabular}{|c|c:c|c|}
\hline ['afa]je & $* \mathrm{FT}^{\varnothing}$ & Dep & $\begin{array}{c}\text { Max } \\
(\mathrm{Ft})\end{array}$ \\
\hline i. afaje & & & $*$ \\
\hline ii. 'afaje & $* !$ & & \\
\hline iii. a'faje & $* !$ & $* !$ & $*$ \\
\hline iv. afa'je & $* !$ & $* !$ & $*$ \\
\hline
\end{tabular}

Third, recessive prestressing suffixes are associated with the RECESSIVE PRESTRESSING cophonology. They assign stress to the last syllable of the

9 I assume that when output stress does not match input stress, this is a consequence of stress deletion and stress reassignment, not stress shift. Hence, candidates (20b.iii, iv) incur violations of $\operatorname{MAx}(\mathrm{Ft})$ and $\operatorname{DeP}(\mathrm{Ft})$, not of $\operatorname{NoF} L O P(F t)$ (for a discussion of NoFLOP constraints, see Alderete 1999, 2001).

10 I assume that each cophonological function uses the same constraints. The only thing that differs between the cophonologies is the ranking of these constraints. In the tableaux below, I show only the highest crucially ranked constants which determine the output. The complete rankings are given in Table III. 
stem unless there is preexisting stress on the stem. This is captured by ranking Align(Stem) in (23), which favours outputs with stress on the last syllable of the stem, below $\operatorname{MAx}(\mathrm{Ft})$ but above $\operatorname{Dep}(\mathrm{Ft})$.

(23) $\operatorname{Align}($ Stem, R; ó, R)

The right edge of the stem is aligned with the right edge of a stressed syllable.

When a recessive prestressing suffix attaches to a stressless stem, ALIGN (Stem) can assign stress to the last syllable of the stem without incurring any violation of the higher-ranking $\operatorname{MAx}(\mathrm{Ft})(24 \mathrm{a})$. When a recessive prestressing suffix attaches to a stressed stem, the higher-ranking $\operatorname{MAx}(\mathrm{Ft})$ prevents stress reassignment, so the output is faithful to the input (24b).

(24) Recessive prestressing

a.

\begin{tabular}{|c|c|c|c|}
\hline$\left[\mathrm{pa}^{\mathrm{n}} \mathrm{dza}\right] \mathrm{Pfa}_{\leftarrow}$ & $\begin{array}{l}\text { Max } \\
(\mathrm{Ft})\end{array}$ & $\begin{array}{c}\text { AliGN } \\
(\mathrm{St})\end{array}$ & $\begin{array}{l}\text { DEP } \\
(F t)\end{array}$ \\
\hline i. $\mathrm{pa}^{\mathrm{n}} \mathrm{dza} f \mathrm{fa}$ & & $* !$ & \\
\hline ii. ' $p a^{n} d z a r f a$ & & $* !$ & $*$ \\
\hline $\log _{3}$ iii. $\mathrm{pa}^{\ln } \mathrm{d} z a$ Pfa & & & * \\
\hline iv. $\mathrm{pa}^{\mathrm{n}} \mathrm{dza} \mathrm{P}^{\prime} \mathrm{fa}$ & & $* !$ & * \\
\hline
\end{tabular}

b.

\begin{tabular}{|r|c|c|c|}
\hline ['afa]Pfa & $\begin{array}{c}\text { Max } \\
(\mathrm{Ft})\end{array}$ & $\begin{array}{c}\text { Align } \\
(\mathrm{St})\end{array}$ & $\begin{array}{c}\text { DeP } \\
(\mathrm{Ft})\end{array}$ \\
\hline i. afa?fa & $* !$ & $*$ & \\
\hline quig ii. 'afarfa & & $*$ & \\
\hline iii. a'fa?fa & $* !$ & & $*$ \\
\hline iv. afa?'fa & $* !$ & $*$ & $*$ \\
\hline
\end{tabular}

Fourth, dominant prestressing suffixes are associated with the DOMINANT PRESTRESSING cophonology. They always place stress on the last syllable of the stem, regardless of the input. This is captured by ranking $\operatorname{Align}(\mathrm{Stem})$ above $\operatorname{MAx}(\mathrm{Ft})$, ensuring that stress is assigned to the last syllable of stressless stems (25a), as well as underlyingly stressed stems (25b).

\section{Dominant prestressing}

a.

\begin{tabular}{|c|c|c|}
\hline$\left[\mathrm{pa}^{\mathrm{n}} \mathrm{dza}\right] \mathrm{hama} \mathrm{t}_{\leftarrow}^{\varnothing}$ & $\operatorname{AligN}(\mathrm{St})$ & $\operatorname{Max}(\mathrm{Ft}) \operatorname{Dep}(\mathrm{Ft})$ \\
\hline i. $\mathrm{pa}^{\mathrm{n}} \mathrm{dzahama}$ & $* !$ & \\
\hline ii. 'pa ${ }^{\mathrm{n}} \mathrm{czahama}$ & *! & * \\
\hline iii. $\mathrm{pa}^{\ln } \mathrm{dzahama}$ & & * \\
\hline iv. pandza'hama & *! & * \\
\hline
\end{tabular}

b.

\begin{tabular}{|r|c|c:c|}
\hline ['afa]hama & ALign(St) & $\operatorname{MAx}(\mathrm{Ft})$ & $\operatorname{Dep}(\mathrm{Ft})$ \\
\hline i. afahama & $* !$ & $*$ & \\
\hline ii. 'afahama & $* !$ & & $*$ \\
\hline iv. aii. a'fahama & & $*$ & $*$ \\
\hline iv. afa'hama & $* !$ & $*$ & $*$ \\
\hline
\end{tabular}

Finally, after all the morphophonological operations have applied, each verb undergoes one final phonological evaluation. The final evaluation is 


\section{Maksymilian Dabkowski}

associated with the PROSODIC WORD cophonology; it prosodifies the verb, assigning stress to the penultimate syllable just in case the output of the last morphophonological operation is stressless. This is captured by ranking Non-finality in (26), which penalises word-final stress, and $\operatorname{Max}(\mathrm{Ft})$, which ensures faithfulness to input stress, above Align(Stem).

(26) Non-finality

The final syllable of a word is not its prosodic head.

Non-finality eliminates candidates with word-final stress. Align(Stem) assigns a violation mark for each syllable intervening between the stressed syllable and the right edge of the stem. The last phonological evaluation (the prosodic word cophonology) is not triggered by a morphological construction associated with a suffix, so the right edge of the stem is coextensive with the right edge of the word. The interaction of Non-FINALITY and Align(Stem) yields penultimate stress, given a stressless input. MAx $(\mathrm{Ft})$ ranks above Align(Stem), ensuring that penultimate stress is assigned only when input stress is absent.

If no suffixes attach to a verb, no morphophonological operations apply, and the only phonological evaluation it undergoes is that associated with the prosodic word cophonology. If the verb is underlyingly stressless, penultimate stress is assigned (27a). If the verb is underlying stressed, that stress is preserved in the output (27b). ${ }^{11}$

Prosodic word
\begin{tabular}{|r|c|c|c|}
\hline atapa $]_{\omega}$ & $\begin{array}{c}\text { Max }_{1} \\
(\mathrm{Ft})\end{array}$ & FIN & $\begin{array}{c}\text { Align } \\
(\mathrm{St})\end{array}$ \\
\hline i. 'atapa & & & $* * !$ \\
\hline ii. a'tapa & & & $*$ \\
\hline iii. ata'pa & & $* !$ & \\
\hline
\end{tabular}

\begin{tabular}{|c|c|c|c|}
\hline$[\text { 'kon dase }]_{\omega}$ & $\begin{array}{l}\text { MaX } \\
(\mathrm{Ft})\end{array}$ & $\begin{array}{l}\text { Non- } \\
\text { FIN }\end{array}$ & $\begin{array}{l}\text { Align } \\
\text { (St) }\end{array}$ \\
\hline i. 'kondase & & & *** \\
\hline ii. $\mathrm{ko}^{\mathrm{In}}$ dase & $* !$ & & * \\
\hline iii. $\mathrm{ko}^{\mathrm{n}} \mathrm{da}$ 'se & *! & $* !$ & \\
\hline
\end{tabular}

The prosodic word cophonology is also responsible for assigning penultimate stress to morphologically complex forms in situations when the output of the last morphophonological operation is stressless, either because stress was never assigned (28a) or because it was deleted by a dominant stressless suffix (28b). If the output of the last morphophonological operation is stressed, the prosodic word evaluation has no effect $(28 \mathrm{c})$. The tableaux show the last cophonological evaluation, which is circled in the morphophonological constituency trees given on the right.

11 In (27), I do not consider the stressless candidates ([atapa], [kondase]). I assume that these are eliminated by a constraint (not shown in the tableaux) which is high-ranked in the prosodic word cophonology and which requires that each lexical word corresponds to a prosodic word, such as Prince \& Smolensky's (1993) LEXICALWORD $\approx$ PROSODICWORD. 
(28) Prosodic word

a.

\begin{tabular}{|c|c|c|}
\hline$\left[\mathrm{pa}^{\mathrm{n}} \mathrm{dzahi}\right]_{\omega}$ & $\begin{array}{c:c}\operatorname{MAX}_{\text {Aan- }} & \text { Non- } \\
(\mathrm{Ft}) & \text { FIN }\end{array}$ & $\begin{array}{c}\text { AligN } \\
(\mathrm{St})\end{array}$ \\
\hline i. ' $\mathrm{pa}^{\mathrm{n}} \mathrm{dzahi}$ & & **! \\
\hline ii. $\mathrm{pa}^{\ln \mathrm{d}} \mathrm{d}$ ahi & & * \\
\hline iii. $\mathrm{pa}^{\mathrm{n}} \mathrm{d} z \mathrm{a}^{\prime} \mathrm{hi}$ & *! & \\
\hline
\end{tabular}

b.

\begin{tabular}{|c|c:c|c|}
\hline$[\text { afaje }]_{\omega}$ & $\begin{array}{c}\text { MAX } \\
(\mathrm{Ft})\end{array}$ & FIN & $\begin{array}{c}\text { Align } \\
(\mathrm{St})\end{array}$ \\
\hline i. 'afaje & & & $* * !$ \\
\hline ii. a'faje & & & $*$ \\
\hline iii. afa'je & & $* !$ & \\
\hline
\end{tabular}

c.

\begin{tabular}{|c|c|c|c|}
\hline$[\text { 'afahi }]_{\omega}$ & $\begin{array}{l}\text { MAI } \\
(\mathrm{Ft})\end{array}$ & $\begin{array}{l}\text { Non- } \\
\text { FIN }\end{array}$ & $\begin{array}{c}\text { Align } \\
(\mathrm{St})\end{array}$ \\
\hline i. 'afahi & & & ** \\
\hline ii. a'fahi & $* !$ & & * \\
\hline iii. afa'hi & $* !$ & *! & \\
\hline
\end{tabular}
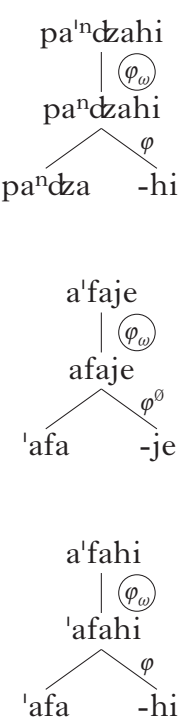

Complete rankings for the five cophonologies are given in (29).

(29) Complete ranking for each of the five cophonologies

$\varphi \quad\{\{\operatorname{Max}(\mathrm{Ft}), \operatorname{Dep}(\mathrm{Ft})\} \gg\{*$ Foot, $\operatorname{Align}(\mathrm{St})\}\}$, Non-fin

$\varphi^{\emptyset}\left\{\left\{*^{*} \mathrm{Foot}, \operatorname{Dep}(\mathrm{Ft})\right\} \gg\{\operatorname{Max}(\mathrm{Ft}), \operatorname{Align}(\mathrm{St})\}\right\}, \operatorname{Non}-\mathrm{Fin}$

$\varphi_{\leftarrow}\{\operatorname{Max}(\mathrm{Ft}) \gg \operatorname{Align}(\mathrm{St}) \gg\{*$ Foot, $\operatorname{Dep}(\mathrm{Ft})\}\}$, Non-Fin

$\varphi_{\leftarrow}^{\emptyset}\{\operatorname{Align}(\mathrm{St}) \gg\{\operatorname{Max}(\mathrm{Ft}), \operatorname{Dep}(\mathrm{Ft}), *$ Foot $\}\}$, Non-Fin

$\varphi_{\omega} \quad\{\operatorname{Max}(\mathrm{Ft}), \mathrm{Non}-\mathrm{Fin}\} \gg \operatorname{Align}(\mathrm{St}) \gg\left\{\mathrm{Dep}(\mathrm{Ft}),{ }^{*} \mathrm{FoOT}\right\}$

During a phonological evaluation associated with a morphological construction, the stem is morphologically differentiated from the suffix (in the tableaux above, the input stems were given in brackets). As a consequence, constraints such as AligN(Stem) can refer to and access stem edges. The output of one phonological evaluation may serve as input to another. However, the phonological evaluation outputs a phonological string, which does not retain morphological information. Thus the next phonological evaluation is blind to the morphophonological constitution of the stem. In other words, the brackets in the input of one phonological evaluation (e.g. (20a)) are absent from the input of the following one (e.g. (28a)). This architectural property of Cophonology Theory predicts that the phonological operations associated with particular suffixes have the same effects on morphologically complex input stems as they have on simplex stems. This prediction is borne out; all verbs forms are captured by the proposed analysis, regardless of their morphological complexity. 


\section{Maksymilian Dabkowski}

Underlyingly stressless verbs with several stressless suffixes (recessive or dominant) receive penultimate stress (30a). Underlyingly stressed verbs with recessive stressless suffixes retain their word-initial stress, as in the first form in (30b). The stress of underlyingly stressed verbs with at least one dominant stressless suffix is erased, followed by default penultimate stress assignment, as in the remaining forms in (b). In the representations below, the first line gives the underlying form of the verb $\left(\right.$ stem $_{1}$ in (18)), followed by all the phonological evaluations that apply (i.e. $s f x_{1}$ triggering $\varphi_{1}, s f x_{2}$ triggering $\varphi_{2}$, etc., followed by postmorphological prosodification, $\left.\varphi_{\omega}\right)$. The second line gives the output of the first morphophonological operation $\left(\right.$ stem $_{2}$, which is the output of applying $\varphi_{1}$ to stem ${ }_{1}$ $s f x_{1}$ ) followed by the remaining morphophonological operations. The penultimate line gives the output of the last morphophonological operation. The last line gives the surface form which results from applying the prosodic word cophonology $\left(\varphi_{\omega}\right)$ to the output of the last morphophonological operation.

\begin{tabular}{|c|c|c|c|}
\hline $\begin{array}{l}\text { a. } \mathrm{p}^{\mathrm{h}} \mathrm{i-na-hi} \varphi_{\omega} \\
\mathrm{p}^{\mathrm{h}} \text { ina-hi } \varphi_{\omega} \\
\mathrm{p}^{\mathrm{h}} \text { inahi } \varphi_{\omega} \\
\mathrm{p}^{\mathrm{h}} \mathrm{i}^{\mathrm{i}} \text { nahi }\end{array}$ & $\begin{array}{l}\mathrm{p}^{\mathrm{h}_{\mathrm{i}}-\mathrm{je}} \mathrm{e}^{\emptyset \mathrm{hi}} \varphi_{\omega} \\
\mathrm{p}^{\mathrm{h}} \text { ije-hi } \varphi_{\omega} \\
\mathrm{p}^{\mathrm{h}} \text { ijehi } \varphi_{\omega} \\
\text { p }^{\mathrm{h}^{\mathrm{i}}{ }^{\prime} \text { jehi }}\end{array}$ & $\begin{array}{l}\mathrm{p}^{\mathrm{h}_{\mathrm{i}} \text { na-je }} \mathrm{e}^{\varnothing} \varphi_{\omega} \\
\mathrm{p}^{\mathrm{h}_{\text {ina-je }}} \varphi_{\omega} \\
\mathrm{p}^{\mathrm{h}_{\text {inane }} \varphi_{\omega}} \\
\mathrm{p}^{\mathrm{h}^{\prime} \text { inane }^{\prime}}\end{array}$ & 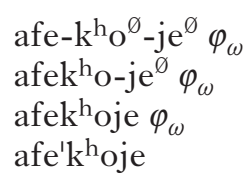 \\
\hline $\begin{array}{l}\text { b. 'afa-ẽ-hi } \varphi_{\omega} \\
\text { 'afaĩ-hi } \varphi_{\omega} \\
\text { 'afaĩhi } \varphi_{\omega} \\
\text { 'afaĩhi }\end{array}$ & $\begin{array}{l}\text { 'afa-je }{ }^{\emptyset}-\text { hi } \varphi_{\omega} \\
\text { afaje-hi } \varphi_{\omega} \\
\text { afajehi } \varphi_{\omega} \\
\text { afa'jehi }\end{array}$ & $\begin{array}{l}\text { 'afa-ẽ-je } \mathrm{e}^{\varnothing} \varphi_{\omega} \\
\text { 'afaĩ-je }{ }^{\varnothing} \varphi_{\omega} \\
\text { afaĩne } \varphi_{\omega} \\
\text { a'faĩne }\end{array}$ & 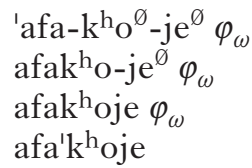 \\
\hline
\end{tabular}

Underlyingly stressless verbs followed first by stressless suffixes (recessive or dominant) and then by recessive prestressing suffixes have stress on the syllable immediately preceding the first recessive prestressing suffix (31a). Underlyingly stressed verbs followed by recessive suffixes (stressless or stressed) retain their initial stress $(31 \mathrm{~b})$.

$$
\begin{aligned}
& \text { a. } \mathrm{p}^{\mathrm{h}} \mathrm{i}-\mathrm{hi}-2 \mathrm{~Pa}_{\leftarrow} \varphi_{\omega} \quad \mathrm{p}^{\mathrm{h}} \mathrm{i}-\mathrm{na}-\mathrm{k}^{\mathrm{h}} \mathrm{O}^{\varnothing}-\mathrm{Pfa} \mathrm{q}_{\leftarrow} \varphi_{\omega} \\
& \mathrm{p}^{\text {hihi-Pfa }} \varphi_{\omega} \quad \mathrm{p}^{\mathrm{h}} \text { ina-k } \mathrm{k}^{\mathrm{h}} \mathrm{o}^{\emptyset}-\mathrm{Pfa} \mathrm{f}_{\leftarrow} \varphi_{\omega} \\
& \mathrm{p}^{\text {hi'hiPfa } \varphi_{\omega}} \quad \mathrm{p}^{\mathrm{h}_{\text {inak }}{ }^{\mathrm{h}} \mathrm{O}-\mathrm{Pfa}} \boldsymbol{\varphi}_{\omega} \\
& \mathrm{p}^{\text {hi'hirfa }} \\
& \text { b. 'afa-hi-Pfa } \leftarrow \varphi_{\omega} \\
& \text { 'afahi-Pfa } \leftarrow \varphi_{\omega} \\
& \text { 'afahipfa } \varphi_{\omega} \\
& \text { 'afahirfa } \\
& \mathrm{p}^{\text {hina' }} \mathrm{k}^{\mathrm{h}} \mathrm{oPfa} \varphi_{\omega} \\
& \mathrm{p}^{\text {hina' }} \mathrm{k}^{\mathrm{h}} \text { orfa } \\
& \text { 'afa-ẽ-hi-Pfa } \leftarrow \varphi_{\omega} \\
& \text { 'afaĩ-hi-Pfa } \varphi_{\omega} \\
& \text { 'afaĩhi-Pfa } \varphi_{\omega} \\
& \text { 'afaĩhiPfa } \varphi_{\omega} \\
& \text { 'afaĩhirfa }
\end{aligned}
$$

$$
\begin{aligned}
& \mathrm{p}^{\mathrm{h}} \text { i-hi-Pfa }-\mathrm{ja} \mathrm{a}_{\leftarrow} \varphi_{\omega} \\
& \mathrm{p}^{\text {hihi-Pfa }} \text {-ja }_{\leftarrow} \varphi_{\omega}
\end{aligned}
$$

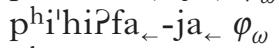

$$
\begin{aligned}
& \mathrm{p}^{\mathrm{h}^{\prime} \text { 'hi?faja } \varphi_{\omega}} \\
& \mathrm{p}^{\text {hi'hirfaja }} \\
& \text { 'afa-hi-Pfa }{ }_{\leftarrow}-\mathrm{ja}_{\leftarrow} \varphi_{\omega} \\
& \text { 'afahi-Pfa }-\mathrm{ja}_{\leftarrow} \varphi_{\omega} \\
& \text { 'afahiPfa-ja } \varphi_{\leftarrow} \varphi_{\omega} \\
& \text { 'afahirfaja } \varphi_{\omega} \\
& \text { 'afahirfaja }
\end{aligned}
$$

The underlying stress of a stressed verb followed by at least one dominant stressless suffix is removed. Then, the first recessive prestressing suffix has a stressless form as its input, and assigns stress to its last syllable (32). 
(32)

$$
\begin{aligned}
& \text { a. ' } a f a-j e^{\varnothing}-P f a_{\leftarrow}-j a_{\leftarrow} \varphi_{\omega} \\
& \text { afaje- } P \mathrm{fa}_{\leftarrow}-\mathrm{ja} \leftarrow \varphi_{\omega} \\
& \text { afa'jePfa-ja } \varphi_{\leftarrow} \varphi_{\omega} \\
& \text { afa'jerfaja } \varphi_{\omega} \\
& \text { afa'jerfaja } \\
& \text { c. 'afa-ẽ- } \mathrm{k}^{\mathrm{h}} \mathrm{O}^{\emptyset}-2 \mathrm{fa}_{\leftarrow} \varphi_{\omega} \\
& \text { 'afaĩ-k }{ }^{\mathrm{h}} \mathrm{O}^{\emptyset}-\mathrm{Pfa}_{\leftarrow} \varphi_{\omega} \\
& \text { afaĩk }^{\mathrm{h}} \mathrm{O}-\mathrm{Pfa}_{\leftarrow} \varphi_{\omega} \\
& \text { afaĩ' } \mathrm{k}^{\mathrm{h}} \mathrm{OPfa} \varphi_{\omega} \\
& \text { afaĩ } k^{\mathrm{h}} \mathrm{OPfa}
\end{aligned}
$$

Dominant prestressing suffixes delete lexical verb stress (33a), as well as prior prestressing (33b). Recessive prestressing suffixes which come after a dominant prestressing suffix do not affect stress (33c). Thus, when a dominant prestressing suffix is present, stress always falls on the syllable immediately to its left.

$$
\begin{aligned}
& \begin{array}{l}
\text { a. 'afa-ẽ-hama }{ }_{\leftarrow}^{\varnothing} \varphi_{\omega} \\
\text { 'afaĩ-hama } \varnothing_{\leftarrow} \varphi_{\omega}
\end{array} \\
& \text { a'faĩhama } \varphi_{\omega} \\
& \text { a'faĩhama } \\
& \text { c. 'afa-hama }{ }_{\leftarrow}^{\varnothing}=\mathrm{te}_{\leftarrow}=\mathrm{ke}_{\leftarrow} \varphi_{\omega} \\
& \text { a'fahama }=\mathrm{te}_{\leftarrow}=\mathrm{ke}_{\leftarrow} \varphi_{\omega} \\
& a^{\prime} \text { fahama }{ }^{\mathrm{n}} \mathrm{de}=\mathrm{ke}_{\leftarrow} \varphi_{\omega} \\
& \text { a'fahaman }{ }^{\text {ndeke }} \varphi_{\omega} \\
& \text { a'fahaman }{ }^{\text {ndeke }}
\end{aligned}
$$

A'ingae verbal roots fall into two stress classes: stressless and stressed. Among morphologically complex forms with exactly two suffixes, the following three combinations are possible: (i) stressless followed by stressless, (ii) stressless followed by prestressing, (iii) prestressing followed by prestressing. A prestressing suffix may not be followed by a stressless one (see Table II). Either of the two suffixes can be recessive or dominant, yielding four different combinations. In total, there are $2 \times 3 \times 4=24$ possible root-sf $x$-sf $x$ combinations, schematised in Table III. Since there are no licit combinations of two dominant prestressing suffixes, only 22 are attested. The account correctly predicts the outputs for all of them.

\section{Alternative frameworks}

Cophonology Theory allows for associating different suffixes with different phonological rankings; it uses non-representational means to capture morpheme-specific phonology. In this section, I sketch the outlines of two alternative representational analyses, couched in Stratal Optimality Theory $(\$ 5.1)$ and the Gradient Symbolic Representations 
Maksymilian Dabkowski

\begin{tabular}{|c|c|c|c|}
\hline \multicolumn{2}{|c|}{ stressless } & \multicolumn{2}{|c|}{ stressed } \\
\hline input & output & input & output \\
\hline $\begin{array}{l}\text { root-sfx-sfx } \\
\text { root-sfx-sfi } \\
\text { root-sfx } x^{\varnothing} \text {-sfx } \\
\text { root-sfx }{ }^{\varnothing} \text {-sfx }\end{array}$ & $\begin{array}{l}\text { root-'sfx-sfx } \\
\text { root-'sfx-sfx } \\
\text { root-'sfx-sfx } \\
\text { root-'sfx-sfx }\end{array}$ & $\begin{array}{l}\text { 'root-sfx-sfx } \\
\text { 'root-sfx-sfx } \\
\text { 'root-sf } x^{\varnothing}-s f x \\
\text { 'root-sfx }{ }^{\varnothing}-s f x^{\varnothing}\end{array}$ & $\begin{array}{l}\text { 'root-sfx-sfx } \\
\text { root-'sfx-sfx } \\
\text { root-'sfx-sfx } \\
\text { root-'sfx-sfx }\end{array}$ \\
\hline $\begin{array}{l}\text { root-sfx-sfx } \\
\text { root-sfx-sfx } \\
\text { root-sfx } x_{\leftarrow}^{\varnothing}-\text { sfx }_{\leftarrow} \\
\text { root-sfx }{ }^{\varnothing}-\text { sfx }_{\leftarrow}^{\varnothing}\end{array}$ & $\begin{array}{l}\text { root-'sfx-sfx } \\
\text { root-'sfx-sfx } \\
\text { root-'sfx-sfx } \\
\text { root-'sfx-sfx }\end{array}$ & $\begin{array}{l}\text { 'root-sfx-sf } x_{\leftarrow} \\
\text { 'root-sfx-sfx } \\
\text { 'root-sfx } \\
\text { 'root-sf }-s x_{\leftarrow}^{\varnothing}-s f x_{\leftarrow}^{\varnothing}\end{array}$ & $\begin{array}{l}\text { 'root-sfx-sfx } \\
\text { root-'sfx-sfx } \\
\text { root-'sfx-sfx } \\
\text { root-'sfx-sfx }\end{array}$ \\
\hline $\begin{array}{l}\text { root-sfx } x_{\leftarrow}-\text { sfx }_{\leftarrow} \\
\text { root-sfx }- \text { sfx } \\
\text { root-sfx } \\
\text { root-sfx }- \text {-sfx } \\
\text { - }- \text { sfx }_{\leftarrow}^{\varnothing}\end{array}$ & $\begin{array}{l}\text { ro'ot-sfx-sfx } \\
\text { root-'sfx-sfx } \\
\text { ro'ot-sfx-sfx } \\
(\text { root-'sfx-sfx) }\end{array}$ & 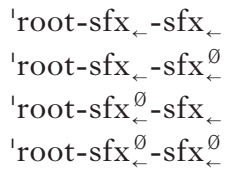 & $\begin{array}{l}\text { 'root-sfx-sfx } \\
\text { root-'sfx-sfx } \\
\text { ro'ot-sfx-sfx } \\
\text { (root-'sfx-sfx) }\end{array}$ \\
\hline
\end{tabular}

Table III

Stress as predicted for the $24(2 \times 3 \times 4)$ root-suffix-suffix combinations.

framework $(\$ 5.2)$. I also consider the representational tools of negative floating stress $(\$ 5.3)$ and empty prosodic nodes $(\$ 5.4)$.

I demonstrate that the representational alternatives struggle with accounting for the full range of A'ingae data. In particular, the dominant stressless suffixes turn out to be the most problematic. The dominant stressless suffixes delete preexisting stress. Thus, their exponence is partially process-like, making it difficult to capture using purely representational means. Overall, the alternative proposals make incorrect predictions or require additional unappealing stipulations.

\subsection{Stratal Optimality Theory}

Classical Optimality Theory (e.g. McCarthy \& Prince 1993a, b, Prince \& Smolensky 1993) models the correspondence between a phonological input and output without recourse to phonological forms in between. Stratal Optimality Theory (e.g. Bermúdez-Otero 1999, 2012, Kiparsky 2000, 2008) relaxes classical OT's ban on intermediate representations by allowing multiple morphophonological strata. Each stratum may be associated with an arbitrarily different ranking of constraints. However, particular morphemes within one stratum may not be associated with morpheme-specific constraint rankings. Differences in phonological operations triggered by different morphemes within one stratum must therefore be captured by various representational means.

In this section, I outline a Stratal O'T analysis of the A'ingae data. The analysis captures most of the observed patterns, including recessive stressless 
suffixes, recessive prestressing suffixes, dominant prestressing suffixes and most configurations involving dominant stressless suffixes. However, it fails to capture forms where a dominant stressless suffix is followed by a recessive stressless suffix and recessive prestressing suffixes. Thus, the Stratal OT analysis will ultimately be rejected. (In $\$ 5.3$, I consider another representational analysis, which uses floating stress to supply the missing representational mechanism by which dominant stressless suffixes delete stress.)

In the Stratal OT analysis, I capitalise on the fact that stressless suffixes (both recessive and dominant) precede prestressing suffixes (again, both recessive and dominant), and propose that they belong to two different strata: stressless to stratum 1 and prestressing to stratum 2. First, I focus on recessive suffixes within each stratum, which I analyse as having no underlying metrical specification. I will later extend the analysis to dominant suffixes, which I analyse metrically.

The two strata are associated with two different constraint rankings. In stratum 1, final stress is assigned unless the verbal root is stressed. This is captured by ranking $\operatorname{MAx}(\mathrm{Ft})$, which ensures the preservation of lexical stress, above AligN(Wd) (34), which favours stress aligned with the right edge of the word.

(34) $\operatorname{Align}($ Word, R; ó, R)

The right edge of the word is aligned with the right edge of a stressed syllable.

In stratum 2, previously assigned stress is retained, except that wordfinal stress is moved to the penultimate syllable. The ban on word-final stress is captured by ranking Non-finality above $\operatorname{Max}(\mathrm{Ft})$. The retraction of final stress onto the penultimate syllable is modelled by ranking $\operatorname{Align}(\mathrm{Wd})$ below $\operatorname{Max}(\mathrm{Ft})$. The constraint rankings for the two strata are given in (35).

$$
\begin{aligned}
& \text { Constraint rankings in the Stratal OT analysis } \\
& \text { stratum } 1 \quad \operatorname{MAx}(\mathrm{Ft}) \gg \operatorname{ALIGN}(\mathrm{Wd}) \\
& \text { stratum } 2 \quad \mathrm{NON}-\mathrm{FIN} \gg \operatorname{MAx}(\mathrm{Ft}) \gg \operatorname{Align}(\mathrm{Wd})
\end{aligned}
$$

The analysis captures the penultimate stress assigned to bare stressless roots. In stratum 1 in (36), stress is assigned to the last syllable of the root. In stratum 2 , that stress is deleted, to avoid a violation of NoNFINALITY. In order to minimise violations of $\operatorname{ALIGN}(\mathrm{Wd})$, stress is then

\begin{tabular}{|c|c|c|}
\hline atapa & $\begin{array}{c}\mathrm{M}_{\mathrm{AX}} \\
(\mathrm{Ft})\end{array}$ & $\begin{array}{l}\text { ALIGN } \\
\text { (Wd) }\end{array}$ \\
\hline a. 'atapa & & $* ! *$ \\
\hline b. a'tapa & & $* !$ \\
\hline c. ata'pa & & \\
\hline
\end{tabular}
assigned to the penultimate syllable (see also note 11).

stratum 2

\begin{tabular}{|r|c|c|c|}
\hline ata'pa & $\begin{array}{c}\text { Non- } \\
\text { FIn }\end{array}$ & $\begin{array}{c}\text { Max } \\
(\mathrm{Ft})\end{array}$ & $\begin{array}{c}\text { Align } \\
(\mathrm{Wd})\end{array}$ \\
\hline a. 'atapa & & $*$ & $* * !$ \\
\hline b. a'tapa & & $*$ & $*$ \\
\hline c. ata'pa & $* !$ & & \\
\hline
\end{tabular}




\section{Maksymilian Dabkowski}

The analysis also captures the preservation of lexically specified stress. In both strata, high-ranked $\operatorname{Max}(\mathrm{Ft})$ ensures that input stress is retained in the output (37).

\section{stratum 1}

\begin{tabular}{|r|c|c|}
\hline 'kon dase & $\begin{array}{c}\text { Max } \\
(\mathrm{Ft})\end{array}$ & $\begin{array}{c}\text { Align } \\
(\mathrm{Wd})\end{array}$ \\
\hline b. ${ }^{\text {a }}$ ' $\mathrm{ko}^{\mathrm{n}}$ dase & & $* *$ \\
\hline b. kon dase & $* !$ & $*$ \\
\hline c. $\mathrm{ko}^{\mathrm{n}}$ da'se & $* !$ & \\
\hline
\end{tabular}

\section{stratum 2}

\begin{tabular}{|r|c|c|c|}
\hline 'kon dase & $\begin{array}{c}\text { Non- } \\
\text { FIN }\end{array}$ & $\begin{array}{c}\text { Max } \\
(\mathrm{Ft})\end{array}$ & $\begin{array}{c}\text { Align } \\
(\mathrm{Wd})\end{array}$ \\
\hline b. ${ }^{\text {a }}$ a. 'kon dase & & & $* *$ \\
\hline c. ${ }^{\text {nn }}$ dase & & $* !$ & $*$ \\
\hline
\end{tabular}

The mechanism seen in (36) is also responsible for the assignment of penultimate stress to underlyingly stressless verbs with stratum 1 suffixes (stressless in Cophonology Theory), as in (38).

\begin{tabular}{|c|c|c|}
\hline 'pa ${ }^{\text {ndza-hi }}$ & $\begin{array}{l}\text { Max } \\
(\mathrm{Ft})\end{array}$ & $\begin{array}{c}\text { ALIGN } \\
(\mathrm{Wd})\end{array}$ \\
\hline a. 'pan ${ }^{\mathrm{n}} \mathrm{zahi}$ & & *!* \\
\hline b. $\mathrm{pa}^{\mathrm{In}} \mathrm{d} z \mathrm{ahi}$ & & $* !$ \\
\hline c. $\mathrm{pa}^{\mathrm{n}} \mathrm{dza}$ 'hi & & \\
\hline
\end{tabular}

stratum 2

\begin{tabular}{|c|c|c|c|}
\hline $\mathrm{pa}^{\mathrm{n}} \mathrm{dza} \mathrm{a}^{\prime} \mathrm{hi}$ & $\begin{array}{c}\text { Non- } \\
\text { FIN }\end{array}$ & $\begin{array}{l}\text { Max } \\
(F t)\end{array}$ & $\begin{array}{c}\text { ALIGN } \\
(\mathrm{Wd})\end{array}$ \\
\hline a. 'pandzahi & & * & **! \\
\hline w b. pa ${ }^{\text {In }}$ dzahi & & * & * \\
\hline c. $\mathrm{pa}^{\mathrm{n}} \mathrm{cza} \mathrm{h}^{\prime} \mathrm{i}$ & $* !$ & & \\
\hline
\end{tabular}

If stratum 2 suffixes (prestressing in Cophonology Theory) are present on a stressless verb, stress falls on the last syllable of the last stratum 1 suffix (or on the last syllable of the verbal root if there are no stratum 1 suffixes). In Stratal OT, this is modelled by assigning final stress to the final syllable in stratum 1 (39a). High-ranking $\operatorname{Max}(F t)$ ensures that this stress is retained in stratum $2(39 \mathrm{~b}){ }^{12}$

\begin{tabular}{|c|c|c|}
\hline 'pandza-hi & $\begin{array}{l}\text { Max } \\
(\mathrm{Ft})\end{array}$ & $\begin{array}{l}\text { ALIGN } \\
(\mathrm{Wd})\end{array}$ \\
\hline a. 'pan ${ }^{\mathrm{n}} \mathrm{dzahi}$ & & $* ! *$ \\
\hline b. pa ${ }^{\text {Indzahi }}$ & & $* !$ \\
\hline c. pandza'hi & & \\
\hline
\end{tabular}

stratum 2

\begin{tabular}{|c|c|c|c|}
\hline $\mathrm{pa}^{\mathrm{n}} \mathrm{cza}$ 'hi-Pfa-ja & $\begin{array}{l}\text { Non- } \\
\text { FIN }\end{array}$ & $\begin{array}{c}\operatorname{Max} \\
(\mathrm{Ft})\end{array}$ & $\begin{array}{c}\text { Align } \\
(\mathrm{Wd})\end{array}$ \\
\hline a. $\mathrm{pa}^{\mathrm{In}} \mathrm{dzahi} f \mathrm{aja}$ & & *! & *** \\
\hline b. pan dza'hiPfaja & & & ** \\
\hline c. $\mathrm{pa}^{\mathrm{n}} \mathrm{dzahi} \mathrm{P}^{\prime} f a j a$ & & *! & * \\
\hline
\end{tabular}

I now turn to dominant suffixes. First, consider dominant prestressing suffixes, which follow stressless suffixes. They therefore belong to stratum 2. However, unlike recessive prestressing suffixes, they always place stress on the syllable which immediately precedes them, regardless of other suffixes present in the derivation. In Stratal OT, this property of dominant prestressing suffixes has to be captured representationally. I

12 Unlike Bermúdez-Otero (2012), I assume non-cyclic application for both strata. 
propose that dominant prestressing suffixes are associated with metrical structure. Specifically, they require that the right edge of a trochaic foot coincide with the right edge of their first syllable. Thus, the underlying form of the 2 nd person imperative suffix is $\left./-k^{\mathrm{h}} \mathrm{a}\right) /$ and the underlying form of the prohibitive suffix is /-ha)ma/. The rest of the trochaic foot is supplied in the output by footing the first syllable of the dominant prestressing suffix and the syllable before it together. This gives rise to prestressing: [...(ók $\left.\left.\mathrm{k}^{\mathrm{a}} \mathrm{a}\right)\right]$, [...(óha)ma].

When a dominant prestressing suffix attaches to a stressed verb (40a) or after another stratum 2 suffix (40b), there are conflicting metrical specifications. Since there can only be one primary stress in a word, a violation of $\operatorname{Max}(\mathrm{Ft})$ is inevitable. Thanks to $\operatorname{ALIGN}(\mathrm{Wd})$, the metrical specification which results in stress closest to the right edge wins. This correctly captures stress assignment with dominant prestressing suffixes. In (40), foot structure is shown explicitly for greater clarity.

stratum 1
\begin{tabular}{|c|c|c|}
\hline ('afa) & $\begin{array}{c}\text { Max } \\
(\mathrm{Ft})\end{array}$ & $\begin{array}{c}\text { AligN } \\
(\mathrm{Wd})\end{array}$ \\
\hline i. ('afa) & & $*$ \\
\hline ii. a('fa) & $* !$ & \\
\hline
\end{tabular}

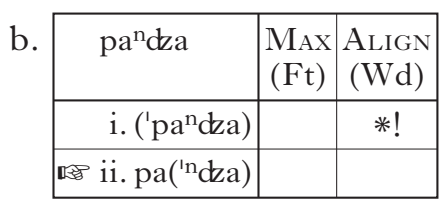

stratum 2

\begin{tabular}{|c|c|c|c|}
\hline ('afa)-ha)ma & $\begin{array}{c}\text { Non- } \\
\text { FIn }\end{array}$ & $\begin{array}{c}\text { Max } \\
\text { (Ft) }\end{array}$ & $\begin{array}{c}\text { Align } \\
\text { (Wd) }\end{array}$ \\
\hline i. ('afa)hama & & $*$ & $* * * !$ \\
\hline ii. a('faha)ma & & $*$ & $* *$ \\
\hline iii. afa('hama) & & $* * !$ & $*$ \\
\hline
\end{tabular}

\begin{tabular}{|r|c|c|c|}
\hline pa('ndza)-Pfa-ha)ma & $\begin{array}{c}\text { Non- } \\
\text { FIN }\end{array}$ & $\begin{array}{c}\text { Max } \\
(\mathrm{Ft})\end{array}$ & $\begin{array}{c}\text { Align } \\
(\mathrm{Wd})\end{array}$ \\
\hline i. pa('ndza?)fahama & & $*$ & $* * * !$ \\
\hline ii. pandza?('faha)ma & & $*$ & $* *$ \\
\hline iii. pan ${ }^{\mathrm{n}} \mathrm{dza}$ ('fa('hama) & & $* * !$ & $*$ \\
\hline
\end{tabular}

Finally, consider dominant stressless suffixes. In Cophonology Theory, these were analysed as triggering the operation of stress deletion without themselves assigning stress. Stress deletion is difficult to capture by representational means - it does not involve listing metrical structure, but rather a demand that metrical structure be erased. As a consequence, attempting to capture the dominant stressless suffixes with purely representational means requires reanalysing the stress deletion associated with them as something fundamentally different.

Observe that in many forms with dominant stressless suffixes, such as the passive $/-\mathrm{je}^{\varnothing} /$, stress falls on the dominant stressless suffix (41a) or moves towards it (41b).
(41) a. /'afa $-\mathrm{je}^{\varnothing}-2 \mathrm{fa}_{\leftarrow} /$
$\left[\begin{array}{lll}\text { afa } & - \text { 'je } & -\mathrm{Pfa}\end{array}\right]$
speak-PASS-PLS
b. /'afa $-\mathrm{je} \mathrm{e}^{\varnothing}$
[a'fa -je]
speak-PASS




\section{Maksymilian Dabkowski}

One might try to leverage this fact by proposing that what I analysed as stress-deleting suffixes are actually 'self-stressed' suffixes. In this reanalysis, the underlying form of the passive is $/-\mathrm{je} /$ and the reciprocal $/-^{-} \mathrm{k}^{\mathrm{h}} \mathrm{O} /$. The Cophonology Theory and the Stratal OT analyses of the four suffixes classes are compared in Table IV, with one suffix representing each class.

\begin{tabular}{|c|c|c|}
\hline suffix & Cophonology Theory & Stratal OT \\
\hline $\begin{array}{l}\text {-hi (PRCM) } \\
-\mathrm{k}^{\mathrm{h}} \mathrm{O}(\mathrm{RECP}) \\
- \text { Pfa (PLS) } \\
\text {-hama (PROH) }\end{array}$ & $\begin{array}{ll}-\mathrm{hi} & \text { recessive stressless } \\
-\mathrm{k}^{\mathrm{h}} \mathrm{O}^{\varnothing} & \text { dominant stressless } \\
-\mathrm{Pfa}_{\leftarrow} & \text { recessive prestressing } \\
-\mathrm{hama}_{\leftarrow} & \text { dominant prestressing }\end{array}$ & $\begin{array}{ll}\text {-hi } & \text { stratum 1 } \\
-' \mathrm{k}^{\mathrm{h}} \mathrm{O} & \text { stratum 1 } \\
\text {-Pfa } & \text { stratum 2 } \\
\text {-ha)ma } & \text { stratum 2 }\end{array}$ \\
\hline
\end{tabular}

\section{Table IV}

Comparison of analyses in Cophonology Theory and Stratal OT.

If there are self-stressed suffixes, there may be multiple stresses in the input. Align(Wd) favours the rightmost of them. Higher-ranking NonFINALITY ensures that a word-final self-stressed suffix does not result in word-final stress. This reanalysis correctly accounts for forms with stratum 1 suffixes only, including forms with one self-stressed suffix, a stressless and a self-stressed suffix, a self-stressed and a stressless suffix and two self-stressed suffixes. An example tableau for a form with two self-stressed suffixes is given in (42).

stratum 1
\begin{tabular}{|r|c|c|}
\hline 'afa-'k $\mathrm{k}^{\mathrm{h}} \mathrm{O}-$ 'je & $\begin{array}{c}\text { Max } \\
(\mathrm{Ft})\end{array}$ & $\begin{array}{c}\text { Align } \\
(\mathrm{Wd})\end{array}$ \\
\hline a. 'afak ${ }^{\mathrm{h}} \mathrm{oje}$ & $* *$ & $* ! * *$ \\
\hline b. a'fak ${ }^{\mathrm{h}} \mathrm{oje}$ & $* * * !$ & $* *$ \\
\hline c. afa' $\mathrm{k}^{\mathrm{h}} \mathrm{oje}$ & $* *$ & $* !$ \\
\hline \multirow{2}{*}{ d. afak ${ }^{\mathrm{h}} \mathrm{o}$ 'je } & $* *$ & \\
\hline
\end{tabular}

stratum 2

\begin{tabular}{|r|c|c|c|}
\hline afak ${ }^{\mathrm{h}}$ 'je & $\begin{array}{c}\text { Non- } \\
\text { FIn }\end{array}$ & $\begin{array}{c}\text { Max } \\
(\mathrm{Ft})\end{array}$ & $\begin{array}{c}\text { Align } \\
(\mathrm{Wd})\end{array}$ \\
\hline a. 'afak ${ }^{\mathrm{h}} \mathrm{oje}$ & & $*$ & $* * ! *$ \\
\hline b. a'fak ${ }^{\mathrm{h}} \mathrm{oje}$ & & $*$ & $* * !$ \\
\hline c. afa' $^{\mathrm{h}} \mathrm{oje}$ & & $*$ & $*$ \\
\hline d. afak $^{\mathrm{h}} \mathrm{o}$ 'je & $* !$ & & \\
\hline
\end{tabular}

The Stratal OT reanalysis correctly accounts for forms with stratum 1 suffixes followed by stratum 2 suffixes, when there is one self-stressed stratum 1 suffix, one stressless stratum 1 suffix followed by a self-stressed one and two self-stressed stratum 1 suffixes. However, the analysis makes an incorrect prediction in the case of a self-stressed suffix followed by a stressless suffix and by a stratum 2 suffix (43). This is in contrast with the Cophonology Theory analysis, which correctly predicts the output form (31b). 
(43)

stratum 1

\begin{tabular}{|r|c|c|}
\hline 'afa-'k $\mathrm{k}^{\mathrm{h}} \mathrm{O}-\mathrm{hi}$ & $\begin{array}{c}\text { Max } \\
(\mathrm{Ft})\end{array}$ & $\begin{array}{c}\text { Align } \\
(\mathrm{Wd})\end{array}$ \\
\hline a. 'afak ${ }^{\mathrm{h}} \mathrm{ohi}$ & $*$ & $* * ! *$ \\
\hline b. a'fak ${ }^{\mathrm{h}}$ ohi & $* * !$ & $* *$ \\
\hline c. afa'k $\mathrm{k}^{\mathrm{h}} \mathrm{ohi}$ & $*$ & $*$ \\
\hline d. afak ${ }^{\mathrm{h}} \mathrm{o}$ 'hi & $* * !$ & \\
\hline
\end{tabular}

stratum 2

\begin{tabular}{|r|c|c|c|}
\hline afa'k ${ }^{\mathrm{h}}$ ohi-?fa & $\begin{array}{c}\text { Non- } \\
\text { FIn }\end{array}$ & $\begin{array}{c}\text { Max } \\
(\mathrm{Ft})\end{array}$ & $\begin{array}{c}\text { Align } \\
(\mathrm{Wd})\end{array}$ \\
\hline a. a'fak ${ }^{\mathrm{h}}$ ohi?fa & & $* !$ & $* * *$ \\
\hline b. afa'k ${ }^{\mathrm{h}}$ ohi?fa & & & $* *$ \\
\hline c. afak $^{\mathrm{h}}$ ' hi?fa & & $* !$ & $*$ \\
\hline d. afak ${ }^{\mathrm{h}}$ ohi?'fa & $* !$ & $*$ & \\
\hline
\end{tabular}

In (43), the reciprocal $/-^{1} \mathrm{k}^{\mathrm{h}} \mathrm{O} /$ incorrectly attracts stress instead of deleting it. This reveals that the dominant stressless suffixes are not selfstressed, but truly stress-deleting. With the set of representational mechanisms considered here, it is not clear how deletion of metrical structure can be modelled as metrical structure. In sum, although successful in accounting for most of the forms, the Stratal OT analysis sketched in this section has to be rejected.

\subsection{Gradient symbolic representations}

Dominant stressless suffixes delete preexisting stress and do not themselves assign stress. In the previous section, I entertained a Stratal OT reanalysis of dominant stressless suffixes as self-stressed, which proved to be empirically inadequate. In the remainder of $\S 5$, I consider whether further representational tools can capture stress deletion triggered by dominant stressless suffixes. First, I consider the Gradient Symbolic Representations framework (henceforth GSR), which allows for variation in the degree to which a segment (or stress) is present in the input. I show that standard GSR representations are insufficient to capture A'ingae stress deletion. I then consider an adaptation of Kushnir's (2019) GSRbased account of accentual dominance in Lithuanian, which involves negatively activated floating material. I show that this adaptation correctly captures A'ingae dominance, but at the cost of remodelling metrical structure as autosegments on a metrical tier. This, I argue, undermines the central predictions of metrical theory, and must also be rejected.

Phonological representations are commonly assumed to be discrete: an element may be present or absent from the input; there is no inbetween. The framework of Gradient Symbolic Representations (Rosen 2016, Smolensky \& Goldrick 2016, Zimmermann 2018, 2019) abandons the discreteness assumption, and allows for partial activation of phonological elements. That is to say, the degree to which a segment (or metrical structure) is present in the input may have any value from 0.0 , which signifies the complete absence of the phonological material, to 1.0, which signifies its full activation. As such, GSR is appropriate for modelling scalar behaviour in phonology.

I will now consider a GSR analysis of the A'ingae data. I will show that the analysis captures most of the observed patterns, including recessive stressless suffixes, recessive prestressing suffixes and dominant prestressing 


\section{Maksymilian Dabkowski}

suffixes. However, the representations used in Rosen (2016), Smolensky \& Goldrick (2016) and Zimmermann $(2018,2019)$ are insufficient to capture stress deletion triggered by dominant stressless suffixes.

Recall the following facts: recessive stressless suffixes do not assign stress; recessive prestressing suffixes assign stress only to stressless inputs; when there are several recessive prestressing suffixes, stress is assigned by the first of them; dominant prestressing suffixes assign stress regardless of anything else. Thus the stress associated with dominant prestressing suffixes wins over any other stress, stressed roots win over recessive prestressing suffixes, but lose to dominant prestressing suffixes, recessive prestressing suffixes win over stressless roots and recessive stressless suffixes, and earlier recessive prestressing suffixes win over later prestressing suffixes. This preference hierarchy is summarised in (44).

\section{(44) Preference hierarchy for stress}

dominant prestressing suffixes $\gg$ stressed roots $\gg$ recessive prestressing suffixes (earlier recessive prestressing suffixes $\gg$ later recessive prestressing suffixes) $\gg$ stressless roots, recessive stressless suffixes

GSR translates the above preference hierarchy into a model in which the elements from each rung of the hierarchy are associated with metrical structure in such a way that activation decreases as we descend the hierarchy. Stressed roots are associated with lexically listed metrical feet. Prestressing suffixes (both recessive and dominant) are associated with the right edge of a trochaic foot aligned with the right edge of their first syllable. Dominant prestressing suffixes win over any other stress - their metrical structure is fully activated (1.0). The metrical structure listed with stressed roots has a lower degree of activation (0.9). After stressed roots come recessive prestressing suffixes, with even lower degrees of activation. Since earlier recessive prestressing suffixes win over later recessive prestressing suffixes, I assume that the further down a recessive prestressing suffix is in the morphological template in Fig. 1, the lower its degree of activation $(0.8,0.7,0.6, \ldots)$. Finally, stressless roots and recessive stressless suffixes, which show no preference for stress, have no metrical structure whatsoever. (Stressless roots and recessive stressless suffixes are stressed only when they are a target of a prestressing suffix or the default penultimate stress assignment.) The Cophonology Theory and the Gradient Symbolic Representations analyses are compared in Table V.

Although both the root and the suffixes may be associated with (partially activated) metrical structure in the input, only one primary stress can emerge in the output. This competition is modelled in OT with gradient constraint violations. Specifically, any metrical structure present in the input but absent from the output violates $\operatorname{Max}(\mathrm{Ft})$ to the extent that the metrical structure is activated in the input. When no metrical structure is present in the input, penultimate stress is assigned. Penultimate stress is modelled as an interaction of Non-Finality and Align(Wd). 


\begin{tabular}{|c|c|c|c|}
\hline morpheme & \multicolumn{2}{|c|}{ Cophonology Theory } & GSR \\
\hline -hama (PROH) & -hama & dominant prest & $-\mathrm{ja})_{1.0} \mathrm{ma}$ \\
\hline 'afa 'speak' & ('afa) & stressed root & $(\text { 'afa })_{0}$ \\
\hline -Pfa (PLS) & $-P f a_{\leftarrow}$ & recessive pres & $-P f a)_{0.8}$ \\
\hline$-\mathrm{ja}(\mathrm{IRR})$ & $-\mathrm{ja}$ & recessive prestre & $-\mathrm{ja})_{0.7}$ \\
\hline -mbi (NEG) & $-\mathrm{mbi}_{\leftarrow}$ & recessive prestressing & $\left.-{ }^{\mathrm{mbi}}\right)_{0.6}$ \\
\hline $\mathrm{pa}^{\mathrm{n}} \mathrm{dza}$ 'hun & $\mathrm{pa}^{\mathrm{n}} \mathrm{cza}$ & stressless root & $\mathrm{pa}^{\mathrm{n}} \mathrm{dza}$ \\
\hline -hi (PRCM) & $-h \mathrm{i}$ & recessive stressless & $-\mathrm{hi}$ \\
\hline
\end{tabular}

\section{Table $V$}

Comparison of analyses in Cophonology Theory and the Gradient Symbolic Representations framework.

Each constraint is associated with a weight $w$. In the model at hand, $\operatorname{Max}(\mathrm{Ft})$ and Non-finality each have a weight of 100 . Align(Wd) has a weight of 1 . The sum of the products of each constraint's weight $w$ and its degree of violation $v$ make up the Harmony score $\left(\mathcal{H}=\sum w v\right)$. The candidate with the lowest Harmony score wins.

The GSR account correctly predicts that in the absence of stress in the input, stress is assigned to the penultimate syllable (45).

\begin{tabular}{|r|c|c|c|r|}
\hline pa $^{\text {ndza-hi }}$ & $\begin{array}{c}\text { Max(Ft) } \\
100\end{array}$ & $\begin{array}{c}\text { NoN-Fin } \\
100\end{array}$ & $\begin{array}{c}\text { Align(Wd) } \\
1\end{array}$ & $\mathcal{H}$ \\
\hline a. ('pa ${ }^{\text {ndza }}$ hi & 0.0 & 0.0 & 2.0 & 2 \\
\hline b. pa('ndzahi) & 0.0 & 0.0 & 1.0 & 1 \\
\hline c. pa ${ }^{\text {n }}$ dza('hi) & 0.0 & 1.0 & 0.0 & 100 \\
\hline
\end{tabular}

The account also correctly predicts that root stress is preserved when only recessive suffixes (either stressless or prestressing) are present. In (46), there are two morphemes in the input which are associated with metrical structure: /('afa)/ 'speak', with 0.9 activation, and /-Pfa)/ (PLS), with 0.8 activation. The winning candidate faithfully preserves the former metrical structure, but not the latter; thus it incurs $0.8 \operatorname{MAx}(\mathrm{Ft})$ violations. Candidates (c) and (d) faithfully preserve the metrical structure listed with /-Pfa)/ at the cost of discarding that of /('afa)/; they each incur 0.9 $\operatorname{Max}(\mathrm{Ft})$ violations. Candidate (b) is faithful to neither; it incurs $0.9+$ $0.8=1.7 \mathrm{MAx}(\mathrm{Ft})$ violations. 


\begin{tabular}{|c|c|c|c|c|}
\hline$(\text { 'afa })_{0.9}$-hi-Pfa $)_{0.8}$ & $\begin{array}{c}\operatorname{Max}(\mathrm{Ft}) \\
100\end{array}$ & $\begin{array}{c}\text { Non-FIN } \\
100\end{array}$ & $\begin{array}{c}\text { Align(Wd) } \\
1\end{array}$ & $\mathcal{H}$ \\
\hline a. ('afa)hirfa & 0.8 & 0.0 & 3.0 & 83 \\
\hline b. a('fahiP)fa & 1.7 & 0.0 & 2.0 & 172 \\
\hline c. afa('hiPfa) & 0.9 & 0.0 & 1.0 & 91 \\
\hline d. afahip('fa) & 0.9 & 1.0 & 0.0 & 190 \\
\hline
\end{tabular}

When the root is stressless, and only recessive suffixes (either stressless or prestressing) are present, the first recessive prestressing suffix assigns stress. The GSR account captures these data as well (47).

\begin{tabular}{|c|c|c|c|c|}
\hline $\left.\mathrm{pa}^{\mathrm{n}} \mathrm{dza}-\mathrm{hi}-\mathrm{Pfa}\right)_{\left.0.8^{-j a}\right)_{0.7}}$ & $\begin{array}{c}\operatorname{Max}(\mathrm{Ft}) \\
100\end{array}$ & $\begin{array}{c}\text { Non-FIN } \\
100\end{array}$ & $\begin{array}{c}\operatorname{Align}(\mathrm{Wd}) \\
1\end{array}$ & $\mathcal{H}$ \\
\hline a. ('pa $\left.\mathrm{p}^{\mathrm{d} z a}\right)$ hiPfaja & 1.5 & 0.0 & 4.0 & 154 \\
\hline b. pa('ndzahi)?faja & 1.5 & 0.0 & 3.0 & 153 \\
\hline c. pa ${ }^{\text {n }}$ dza('hiPfa)ja & 0.7 & 0.0 & 2.0 & 72 \\
\hline d. pa ${ }^{\mathrm{n}} \mathrm{dzahi}($ ('faja) & 0.8 & 0.0 & 1.0 & 81 \\
\hline e. $\mathrm{pa}^{\mathrm{n}} \mathrm{d}$ ahirfa('ja) & 0.8 & 1.0 & 0.0 & 180 \\
\hline
\end{tabular}

Finally, a dominant prestressing suffix always assigns stress, winning over root stress as well as recessive prestressing suffixes (48).

\begin{tabular}{|c|c|c|c|c|}
\hline$\left.\left.(\text { 'afa })_{0.9}-\mathrm{Pfa}\right)_{0.8}-\mathrm{ja}\right)_{1.0} \mathrm{ma}$ & $\begin{array}{c}\operatorname{Max}(\mathrm{Ft}) \\
100\end{array}$ & $\begin{array}{c}\text { Non-FIN } \\
100\end{array}$ & $\begin{array}{c}\operatorname{ALIGN}(\mathrm{Wd}) \\
1\end{array}$ & $\mathcal{H}$ \\
\hline a. ('afar)fahama & 1.8 & 0.0 & 4.0 & 184 \\
\hline b. a('farfa)hama & 1.9 & 0.0 & 3.0 & 193 \\
\hline c. afa?('faha)ma & 1.7 & 0.0 & 2.0 & 172 \\
\hline d. afarfa('hama) & 2.7 & 0.0 & 1.0 & 271 \\
\hline e. afarfaha('ma) & 2.7 & 1.0 & 0.0 & 370 \\
\hline
\end{tabular}

We see that the GSR analysis accounts for forms containing stressless roots, stressed roots, recessive stressless suffixes, recessive prestressing suffixes and dominant prestressing suffixes. However, the gradient symbolic representations used so far do not capture the stress deletion triggered by dominant stressless suffixes. Dominant stressless suffixes do not have any preference for stress assignment. Thus, they are located on the lowest rung of the preference hierarchy, along with stressless roots and recessive stressless suffixes (44). However, they also have the property of deleting preexisting stress, which is not captured by ranking them with respect to other suffixes or assigning them metrical structure of some intermediate degree of activation.

Given that positive stress preference is modelled by metrical structure of positive activation (more than 0.0 , up to 1.0 ), one might consider 
modelling stress deletion with metrical structure of negative activation, say -1.0. In this proposal, dominant stressless morphemes are associated with 'negative stress', modelled as alignment with a negatively activated metrical foot, e.g. $-\left({ }_{-1.0} \mathrm{k}^{\mathrm{h}} \mathrm{O}\right.$ (RECP). This proposal still fails to correctly predict the winner, as shown in (49).

\begin{tabular}{|c|c|c|c|c|}
\hline ('afa $)_{0.9^{-}}\left(-1.0 \mathrm{k}^{\mathrm{h}} \mathrm{o}-\mathrm{hi}-\mathrm{Pfa}\right)_{0.8}$ & $\begin{array}{c}\operatorname{Max}(\mathrm{Ft}) \\
100\end{array}$ & $\begin{array}{c}\text { Non-fin } \\
100\end{array}$ & $\begin{array}{c}\operatorname{Align}(\mathrm{Wd}) \\
1\end{array}$ & $\mathcal{H}$ \\
\hline a. ('afa)k $\mathrm{k}^{\mathrm{h}}$ ohiPfa & -0.2 & 0.0 & 4.0 & -16 \\
\hline b. a('fak $\left.{ }^{\mathrm{h}} \mathrm{o}\right) \mathrm{hiPfa}$ & 0.7 & 0.0 & 3.0 & 73 \\
\hline c. afa(' $\mathrm{k}^{\mathrm{h}}$ ohir)fa & 1.7 & 0.0 & 2.0 & 172 \\
\hline d. afak ${ }^{\mathrm{h}} \mathrm{o}($ 'hirfa) & -0.1 & 0.0 & 1.0 & -9 \\
\hline e. afakhohir('fa) $^{\mathrm{h}}$ & -0.1 & 1.0 & 0.0 & 90 \\
\hline
\end{tabular}

Negatively activated metrical structure listed with a suffix does not interact with the preexisting metrical structure of the root. Thus it does not delete preceding stress; it only additionally rewards lack of stress on the suffix in question. I therefore reject the GSR account as incapable of capturing the stress deletion triggered by dominant stressless suffixes.

\subsection{Floating metrical stress}

In the previous section, I argued that the gradient symbolic representations used in Rosen (2016), Smolensky \& Goldrick (2016) and Zimmermann $(2018,2019)$ are insufficient to account for A'ingae stress deletion triggered by dominant stressless suffixes. The key example was (49), where negatively activated metrical structure failed to delete stress. However, if that negatively activated metrical structure were able to somehow target preceding stress, the GSR proposal would be capable of modelling stress deletion.

An account that allows negatively activated accent to target the accent of the base is proposed by Kushnir (2019) for Lithuanian. Lithuanian is similar to A'ingae in having a complex system of accentual dominance, with strong and weak suffixes as well as dominance phenomena similar to the one discussed above. However, unlike Lithuanian, A'ingae has metrical stress, not pitch accent: A'ingae stress is culminative and obligatory at the level of the phonological word, it correlates with increased duration and intensity (Repetti-Ludlow et al. 2019) and it is accompanied by alternating secondary stress (17).

In the rest of this section, I give an overview of Kushnir's (2019) treatment of dominance, which in Lithuanian involves a weakening of the root's pitch accent. I propose an adaption of the account for A'ingae, but observe that the adaptation requires an autosegmental analysis of stress. I argue that an autosegmental analysis of stress is undesirable, since autosegments and stress have very different, sometimes opposing, typological properties. The autosegmental analysis would undermine the successful 


\section{Maksymilian Dabkowski}

predictions of metrical theory and simultaneously predict many unattested stress patterns and operations. I conclude that the solution advanced by Kushnir should not be extended to the metrical stress of A'ingae.

Lithuanian is a pitch accent language, with one high tone $(\mathrm{H})$ per phonological word. The tone-bearing unit (TBU) is the mora. Thus, in a bimoraic syllable, either mora can be linked to the high tone. This derives the difference between falling pitch contour (known traditionally as 'acute accent') (50a) and raising pitch contour ('circumflex accent') (50b) in bimoraic syllables (data from Kushnir 2019: 34).

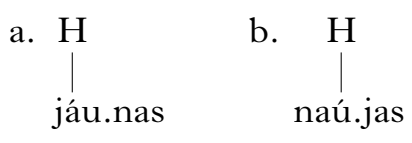

Some Lithuanian morphemes are dominant - they weaken the pitch accent of the stem they attach to. Strong accent is represented with a double acute. Weak accent is represented with an acute accent. Kushnir models this by proposing that dominant morphemes are associated with an unassociated negatively activated tonal autosegment, i.e. a negative floating tone. Floating autosegments are given in dashed boxes. Kushnir proposes that the floating tone may coalesce with the root tone. This is to say, two tones may become one. Coalescence is represented with a squiggly left arrow. The floating tone is negatively activated. Thus, upon coalescence, it diminishes the activity of the root tone (51) (data from Kushnir 2019: 107).

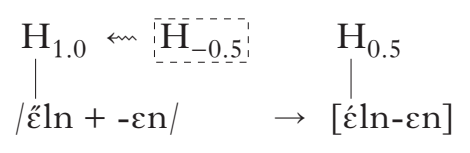

Kushnir's analysis could be adapted for A'ingae. However, A'ingae has metrical stress, not pitch accent. This means that an adaptation of Kushnir's account for A'ingae would require floating stress. Specifically, in this reanalysis, a dominant stressless morpheme is associated with a negatively activated metrical grid mark. The negative grid mark coalesces with the root stress, deactivating it (52). This mechanism can be combined with the analyses sketched out in this section and in $\S 5.1$. In this way, floating stress may supply the missing representational mechanism by which dominant stressless suffixes delete stress.

$$
\times_{0.9} \operatorname{afa}+-\mathrm{k}^{\mathrm{h}} \mathrm{O} / \mathrm{\textrm {x } _ { - }} \rightarrow\left[\mathrm{afa}-\mathrm{k}^{\mathrm{h}} \mathrm{O}\right]
$$

However, this adaptation is not unproblematic. Floating tone, which Kushnir relies on in his analysis, is a natural consequence of modelling tone as autosegments. Stress, however, shows a number of typological properties which differentiate it from autosegments (Hayes 1995: 24-26, 
Hyman 2016). To address this, Hayes (1995) uses the metrical grid to model stress. The resulting representations successfully capture the properties of stress, but make the notion of floating stress incoherent. Floating stress requires an autosegmental analysis of stress - but this comes at the cost of undermining the predictions of metrical theory.

Autosegmental theory posits the existence of separate tiers populated by different types of autosegments, or bundles of phonological features (Goldsmith 1976). Its architecture allows for a number of non-isomorphisms between tones (T) and TBUs $(\tau)$. First, there may be multiple tones linked to one TBU (53a). Second, there may be multiple TBUs linked to one tone $(53 \mathrm{~b})$. Third, there may be TBUs unassociated with any tone (53c). Fourth, there may be tones unassociated with any TBUs, i.e. floating tones $(53 \mathrm{~d})$.
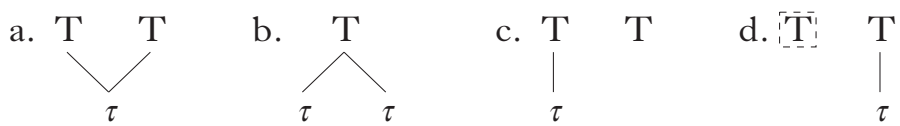

Likewise, the autosegmental architecture naturally models changes in association between autosegments. Specifically, a tone may spread, associating to new TBUs. For example, in Guébie, the definite suffix $/-\mathrm{a} /$ is underlyingly toneless, and the melody of the noun spreads onto it (54) (Sande 2017: 245).

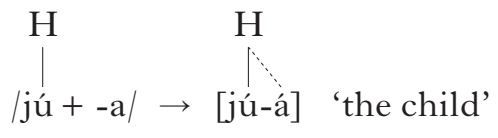

Tones may also delink from their TBUs. For example, in KukiThaadow (Hyman 2010), each non-final tone delinks from its TBU and relinks one TBU to the right. In other words, each non-final tone shifts by one TBU. As a consequence, the final TBU may end up realising two tones. In addition, a boundary low tone $(\% \mathrm{~L})$ associates with the first TBU (55).

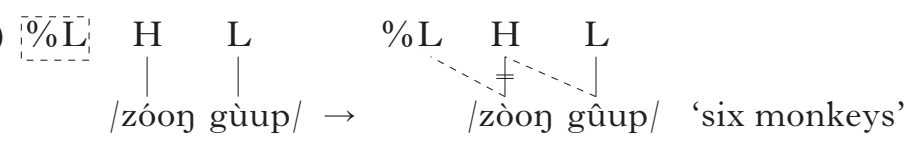

In contrast with the above characteristics and operations of tone, metrical stress has a very different set of typological properties. Unlike tone, metrical stress is culminative and obligatory, so each phonological word has exactly one primary stress. Importantly, stress tends to be distributed rhythmically, and never assimilates (Hayes 1995: 25-26).

The rhythmical distribution of stress means that stressed syllables tend to alternate with stressless syllables. Compare the English form in (56a), where (secondary) stress falls on every other syllable, with the aberrant 


\section{Maksymilian Dabkowski}

(56b), where stress clusters towards the end of the word. The latter clustering of stress is cross-linguistically completely unattested.

(56) a. Apa,lachi'cola

b. *Apala chi $_{1}$ 'o'la

Moreover, stress never assimilates. In the aberrant (57a), the suffix gains secondary stress from the stressed root. This sort of 'stress spreading' is again entirely unattested - unlike tonal spreading, which is common (cf. (54)). In fact, stress tends to dissimilate. When two consecutive syllables carry stress, one of them often undergoes destressing or stress is shifted, as in (57b).
a. ${ }^{*}$ child + -ren $\rightarrow$ 'child-,ren
b. fif'teen 'chairs $\rightarrow$ 'fifteen 'chairs

To account for these properties of stress, Hayes (1995: 8) proposes that metrical stress is not a phonological feature (or a set thereof), but rather a linguistic manifestation of rhythmic structure. Concomitantly, the representation adopted for metrical stress is a hierarchical grouping of metrical units (syllables) into headed constituents (58).

(58) a.

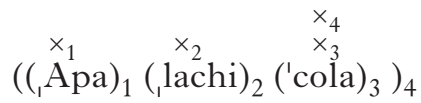

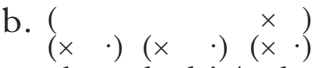

Apa ,lachi 'cola

In (58a), Hayes' (1995: 39) formal representation is given: syllables are grouped into (indexed) feet headed by the rhythmic beats $x_{1}, x_{2}$ and $x_{3}$. The three feet make up a larger metrical constituent (a word), headed by $\times_{4}$. In (58b), the more familiar, though formally less precise, bracketed metrical grid representation is given.

Many of the properties of stress follow from the above representation. The fact that stress tends to rhythmically alternate follows from grouping syllables into binary constituents. The fact that each phonological word has precisely one primary stress follows from the requirement that each word must be headed. Finally, destressing and stress shift in clash can be easily stated as rules operating on grid marks (Hayes 1995: 35, 37).

In Hayes' proposal, stress is modelled as a grouping of metrical units. Importantly, the grouping of metrical units does not involve a separate tier with metrical autosegments. Consequently, in Hayes' model, it is incoherent to speak of association lines between stress and stress-bearing units, or of stress linking, delinking, spreading or floating. ${ }^{13}$

For 'floating stress' to be conceptually coherent, one must abandon metrical theory in favour of an autosegmental theory of stress. An

13 This is not to say that morphemes cannot be integrated into (defective) metrical constituents, as was assumed in $\$ 5.1$ or, for that matter, in many classic works on metrical theory, including Halle \& Vergnaud (1987). The nature of morpheme-specific metrication, however, is different from autosegmental linking, as evidenced by the different phonological processes that characterise the two different types of representations. 
autosegmental theory of stress, however, fails to straightforwardly account for its central properties (culminativity, obligatoriness, rhythmic distribution, lack of assimilation, etc.), while predicting a number of completely unattested stress operations.

For example, consider the non-existent language English', which shows various stress rules similar to the tonal rules of Kuki-Thaadow. In the English' phrase $a$ 'chair to 'sit 'in, there are three primary stresses (three phonological words) in the underlying form. In the surface form, a boundary floating stress $(\% \times)$ associates with the first syllable. Moreover, the stress of chair spreads onto the following phonological clitic to, resulting in one stress associated with two syllables. Finally, the stress of sit delinks and associates with the following phonological word in, resulting in two stresses on one syllable (59).

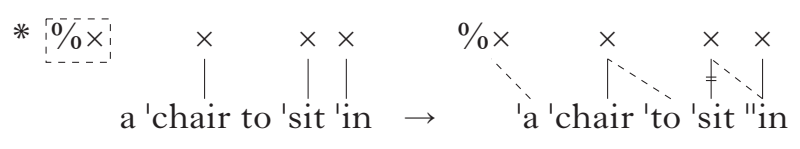

English' shows a number of exotic stress configurations, including floating boundary stress, stress spreading, stressless phonological words and doubly stressed syllables. The existence of any and all of the stress operations seen in English' is predicted by an autosegmental treatment of stress, yet none of these properties is ever attested. I conclude that 'floating stress' is not a viable analytical option, and reject the metrical adaptation of Kushnir's (2019) analysis to A'ingae.

\subsection{Empty prosodic nodes}

Finally, a reviewer suggests modelling the stress deletion triggered by A'ingae dominant stressless suffixes with defective prosodic nodes. Segmentally empty prosodic nodes, including moras (e.g. SamekLodovici 1992, Saba Kirchner 2010), syllables (e.g. Bermúdez-Otero 2012) and feet (e.g. van Oostendorp 2012), have been proposed to model phenomena such as morphological gemination, vowel lengthening, and stress assignment and reduplication.

Trommer \& Zimmermann (2014) extend the representational apparatus of empty prosodic nodes to model subtractive morphology. For example, in Tohono O'odham, the perfect form of a verb is derived from the imperfect by removing its last mora (60) (Fitzgerald \& Fountain 1995: 5-6, Trommer \& Zimmermann (2014: 467).

(60)

$\begin{array}{lll}\text { imperfect } & \text { perfect } & \\ \text { 'ma:k } & \text { 'ma: } & \text { 'give' } \\ \text { 'hi:nk } & \text { 'hi:n } & \text { 'bark' } \\ \text { 'hihim } & \text { 'hihi } & \text { 'walk.PL' }\end{array}$




\section{Maksymilian Dabkowski}

Trommer \& Zimmermann (2014: 485) analyse this as suffixation of a defective segmentally empty mora $-\mu$ (PRF). Given an appropriate constraint ranking, the defective moraic suffix links to the last segment of the word and delinks it from its moraic node in the input (61). The phonetic consequence of this process is that the last segment is not pronounced. In this way, the segmentally empty moraic suffix models the Tohono O'odham productive perfect subtractive morphology.

$$
\begin{aligned}
& \text { /'ma:k- } \mu / \rightarrow \text { ['ma: }] \\
& \text { give }-\mathrm{PRF}
\end{aligned}
$$
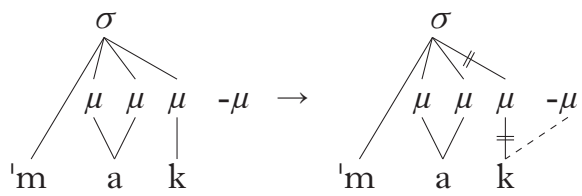

Given that stress is a property of syllables, not moras, an adaptation of Trommer \& Zimmermann's (2014) model to A'ingae might involve the suffixation of a morpheme with a segmentally empty syllable. ${ }^{14}$ In this model, the dominant stressless, or stress-deleting, suffixes would have the underlying representations $/-\sigma \mathrm{k}^{\mathrm{h}} \mathrm{O} /$ (RECP) and /-oje/ (PASs).

The most immediate problem with the above is that the linking of segmental content to an empty syllable node and delinking it from its input syllable node lead to the deletion of the entire syllable, not just stress (62).

$$
* / \operatorname{afa}-\mathrm{k}^{\mathrm{h}} \mathrm{O} / \rightarrow\left[\mathrm{fa}-\mathrm{k}^{\mathrm{h}} \mathrm{o}\right]
$$
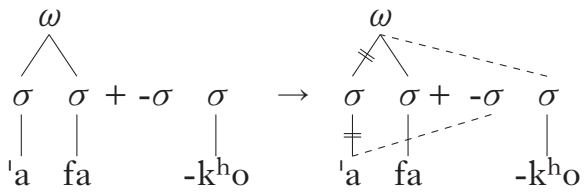

Another problem is that of locality. In Tohono O'odham, the suffix which triggers mora deletion targets the last mora of the word, which is adjacent to the suffix. In A'ingae, the stress-deleting suffixes need not be adjacent to the stressed syllable. In the example above, this results in crossing association lines, which are commonly assumed to be ill-formed (Goldsmith 1976). Given these considerations, I reject the empty prosodic nodes analysis.

\section{Conclusions}

In this study, I showed that the assignment of stress in A'ingae can be most simply modelled as an interaction between two binary parameters: the presence or lack of prestressing and the presence or lack of stress deletion (i.e. dominance). I formalised my account in Cophonology Theory (Orgun 1996, Anttila 1997), a parsimonious framework of the phonology-morphology interface, which captured all the key aspects of the A'ingae data.

14 Another option involves the suffixation of a morpheme with a segmentally empty foot. Either analysis eventually runs into the same problems. 
I showed that dominant stressless suffixes cause the deletion of preceding stress. Their exponence is process-like, making it difficult to capture in a purely representational fashion. I explicitly considered analyses couched in Stratal OT and Gradient Symbolic Representations, as well as the representational tools of floating metrical stress and empty prosodic nodes. I concluded that these representational alternatives either fail to capture the stress deletion triggered by A'ingae dominant stressless morphemes or require additional stipulations which make them empirically unattractive.

Many recent advances in phonological theory have proposed purely representational approaches to process morphology (e.g. Bermúdez-Otero 2012, Trommer \& Zimmermann 2014, Zimmermann 2018, 2019, Jaker $\&$ Kiparsky 2020). At the same time, another current has argued for capturing morphological processes as such, often retaining simpler underlying representations and eschewing some of the abstraction seen in the other theories (e.g. Orgun 1996, Inkelas \& Zoll 2007, Sande et al. 2020). My results support the latter approach - certain phonological operations specific to particular morphemes must be modelled as processes, via either minor rules or constraint reranking, and not by complexifying the underlying symbolic representations of these morphemes.

\section{REFERENCES}

Alderete, John D. (1999). Morphologically governed accent in Optimality Theory. PhD dissertation, University of Massachusetts, Amherst.

Alderete, John D. (2001). Dominance effects as transderivational anti-faithfulness. Phonology 18. 201-253.

AnderBois, Scott (2017). An illocutionary account of reportative evidentials in imperatives. In Dan Burgdorf, Jacob Collard, Sireemas Maspong \& Brynhildur Stefánsdóttir (eds.) Proceedings of the 27th Semantics and Linguistic Theory Conference. 459-479. https://doi.org/10.3765/salt.v27i0.4172.

AnderBois, Scott \& Maksymilian Dąbkowski (2020). A'ingae =sa'ne 'APPR' and the semantic typology of apprehensional adjuncts. In Joseph Rhyne, Kaelyn Lamp, Nicole Dreier \& Chloe Kwon (eds.) Proceedings of the 30th Semantics and Linguistic Theory Conference. 43-62. https://doi.org/10.3765/salt.v30i0.4804.

Anttila, Arto (1997). Variation in Finnish phonology and morphology. PhD dissertation, Stanford University.

Benua, Laura (1997). Transderivational identity: phonological relations between words. PhD dissertation, University of Massachusetts, Amherst.

Bermúdez-Otero, Ricardo (1999). Constraint interaction in language change: quantity in English and Germanic. PhD dissertation, University of Manchester \& University of Santiago de Compostela.

Bermúdez-Otero, Ricardo (2012). The architecture of grammar and the division of labor in exponence. In Jochen Trommer (ed.) The morphology and phonology of exponence. Oxford: Oxford University Press. 8-83.

Blaser, Magdalena \& María Enma Chica Umenda (2008). A'indeccu canqque'sune condase'cho: mitos del pueblo cofán. Sucumbíos: Centro Cultural de Investigaciones Indígenas Padre Ramón López.

Borman, M. B. (1962). Cofán phonemes. In Benjamin Elson (ed.) Studies in Ecuadorian Indian languages. Vol. 1. Norman: Summer Institute of Linguistics of the University of Oklahoma. 45-59. 


\section{Maksymilian Dąbkowski}

Borman, M. B. (1976). Vocabulario cofán: cofán-castellano, castellano-cofán. Quito: Instituto Lingüístico de Verano.

Caballero, Gabriela (2011). Morphologically conditioned stress assignment in Choguita Rarámuri. Linguistics 49. 749-790.

Chomsky, Noam \& Morris Halle (1968). The sound pattern of English. New York: Harper \& Row.

Dąbkowski, Maksymilian (2019). The morphophonology of A'ingae verbal stress. Honors thesis, Brown University. https://ling.auf.net/lingbuzz/005879.

Dąbkowski, Maksymilian (2021a). A'ingae (Ecuador and Colombia) - language snapshot. Language Documentation and Description 20. 1-12. http://www.elpublishing. $\operatorname{org} / \mathrm{PID} / 223$.

Dąbkowski, Maksymilian (2021b). The morphophonology of A'ingae verbal stress. WCCFL 38. 137-146.

Dąbkowski, Maksymilian (2021c). A'ingae second-position clitics are matrix C-heads. In Proceedings of the Workshop on Structure and Constituency in the Languages of the Americas 25. Vancouver, BC: University of British Columbia Working Papers in Linguistics.

Dąbkowski, Maksymilian (in press). Laryngeal feet in A'ingae: implications for metrical theory. WCCFL 39.

Dąbkowski, Maksymilian \& Scott AnderBois (2021). Rationale and precautioning clauses: insights from A'ingae. Ms, University of California, Berkeley \& Brown University.

Dąbkowski, Maksymilian \& Scott AnderBois (in press). The apprehensional domain in A’ingae (Cofán). In Marine Vuillermet, Martina Faller \& Eva Schultze-Berndt (eds.) A typology of apprehensives. Berlin: Language Science Press.

Fischer, Rafael \& Kees Hengeveld (in press). A'ingae (Cofán/Kofán). In Patience Epps \& Lev Michael (eds.) Amazonian languages: an international handbook. Vol. 1: Language isolates. Berlin: De Gruyter Mouton.

Fitzgerald, Colleen \& Amy Fountain (1995). The optimal account of Tohono O'odham truncation. Ms, University of Arizona.

Goldsmith, John A. (1976). Autosegmental phonology. PhD dissertation, MIT.

Halle, Morris \& Jean-Roger Vergnaud (1987). An essay on stress. Cambridge, MA: MIT Press.

Hayes, Bruce (1995). Metrical stress theory: principles and case studies. Chicago: University of Chicago Press.

Hyman, Larry M. (2010). Kuki-Thaadow: an African tone system in Southeast Asia. In Franck Floricic (ed.) Essais de typologie et de linguistique générale: mélanges offerts à Denis Creissels. Lyon: Presses de l'École Normale Supérieure. 31-51.

Hyman, Larry M. (2016). Amazonia and the typology of tone systems. In Heriberto Avelino, Matt Coler \& Leo Wetzels (eds.) The phonetics and phonology of laryngeal features in Native American languages. Leiden \& Boston: Brill. 235-257.

Inkelas, Sharon (1998). The theoretical status of morphologically conditioned phonology: a case study of dominance effects. Yearbook of Morphology 1997. 121-155.

Inkelas, Sharon, C. Orhan Orgun \& Cheryl Zoll (1997). The implications of lexical exceptions for the nature of grammar. In Iggy Roca (ed.) Derivations and constraints in phonology. Oxford: Clarendon. 393-418. Reprinted 2004 in John J. McCarthy (ed.) Optimality Theory in phonology. Oxford: Blackwell. 542-551.

Inkelas, Sharon \& Cheryl Zoll (2005). Reduplication: doubling in morphology. Cambridge: Cambridge University Press.

Inkelas, Sharon \& Cheryl Zoll (2007). Is grammar dependence real? A comparison between cophonological and indexed constraint approaches to morphologically conditioned phonology. Linguistics 45. 133-171.

Itô, Junko \& Armin Mester (1999). The phonological lexicon. In Natsuko Tsujimura (ed.) The handbook of Fapanese linguistics. Malden, MA \& Oxford: Blackwell. 62-100. 
Jaker, Alessandro \& Paul Kiparsky (2020). Level ordering and opacity in Tetsọt'ıné: a Stratal OT account. Phonology 37. 617-655.

Kawahara, Shigeto (2015). The phonology of Japanese accent. In Haruo Kubozono (ed.) The handbook of Fapanese phonetics and phonology. Berlin: de Gruyter Mouton. 445-492.

Kiparsky, Paul (2000). Opacity and cyclicity. The Linguistic Review 17. 351-365.

Kiparsky, Paul (2008). Fenno-Swedish quantity: contrast in Stratal OT. In Vaux \& Nevins (2008). 185-219.

Kiparsky, Paul (2010). Compositional vs. paradigmatic approaches to accent and ablaut. In Stephanie W. Jamison, H. Craig Melchert \& Brent Vine (eds.) Proceedings of the 21st Annual UCLA Indo-European Conference: October 30th and 31st, 2009. Bremen: Hempen. 137-181.

Kushnir, Yuriy (2019). Prosodic patterns in Lithuanian morphology. PhD thesis, University of Leipzig.

McCarthy, John J. \& Alan Prince (1993a). Generalized alignment. Yearbook of Morphology 1993. 79-153.

McCarthy, John J. \& Alan Prince (1993b). Prosodic morphology: constraint interaction and satisfaction. Ms, University of Massachusetts, Amherst \& Rutgers University. Available as ROA-482 from the Rutgers Optimality Archive.

Oostendorp, Marc van (2012). Stress as a proclitic in Modern Greek. Lingua 122. 1165-1181.

Orgun, C. Orhan (1996). Sign-based morphology and phonology with special attention to Optimality Theory. $\mathrm{PhD}$ dissertation, University of California, Berkeley.

Pater, Joe (2009). Morpheme-specific phonology: constraint indexation and inconsistency resolution. In Steve Parker (ed.) Phonological argumentation: essays on evidence and motivation. London: Equinox. 123-154.

Prince, Alan \& Paul Smolensky (1993). Optimality Theory: constraint interaction in generative grammar. Ms, Rutgers University \& University of Colorado, Boulder.

Repetti-Ludlow, Chiara, Haoru Zhang, Hugo Lucitante, Scott AnderBois \& Chelsea Sanker (2019). A'ingae (Cofán). Fournal of the International Phonetic Association 50. 431-444.

Revithiadou, Anthi (1999). Headmost accent wins: head dominance and ideal prosodic form in lexical accent systems. PhD dissertation, University of Leiden.

Rolle, Nicholas (2018). Grammatical tone: typology, theory, and functional load. PhD dissertation, University of California, Berkeley.

Rosen, Eric (2016). Predicting the unpredictable: capturing the apparent semi-regularity of rendaku voicing in Japanese through Harmonic Grammar. BLS 42. 235-249.

Saba Kirchner, Jesse (2010). Minimal Reduplication. PhD dissertation, University of California, Santa Cruz.

Samek-Lodovici, Vieri (1994). A unified analysis of crosslinguistic morphological gemination. In Peter Ackema \& Maaike Schoorlemmer (eds.) ConSole I proceedings. The Hague: Holland Academic Graphics. 265-283.

Sande, Hannah (2017). Distributing morphologically conditioned phonology: three case studies from Guébie. PhD dissertation, University of California, Berkeley.

Sande, Hannah (2019). A unified account of conditioned phonological alternations: evidence from Guébie. $\operatorname{Lg}$ 95. 456-497.

Sande, Hannah (2020). Morphologically conditioned phonology with two triggers. Phonology 37. 453-493.

Sande, Hannah, Peter Jenks \& Sharon Inkelas (2020). Cophonologies by ph(r)ase. NLLT 38. 1211-1261.

Sanker, Chelsea \& Scott AnderBois (2021). Reconstruction of nasality and other aspects of A'ingae phonology. Ms, Yale University \& Brown University. 


\section{Maksymilian Dabkowski}

Smolensky, Paul \& Matthew Goldrick (2016). Gradient symbolic representations in grammar: the case of French liaison. Ms, Johns Hopkins University \& Northwestern University. Available as ROA-1286 from the Rutgers Optimality Archive.

Trommer, Jochen \& Eva Zimmermann (2014). Generalised mora affixation and quantity-manipulating morphology. Phonology 31. 463-510.

Vaux, Bert (2008). Why the phonological component must be serial and rule-based. In Vaux \& Nevins (2008). 20-60.

Vaux, Bert \& Andrew Nevins (eds.) (2008). Rules, constraints, and phonological phenomena. Oxford: Oxford University Press.

Vaxman, Alexandre (2016). How to beat without feet: weight scales and parameter dependencies in the computation of word accent. $\mathrm{PhD}$ dissertation, University of Connecticut.

Zimmermann, Eva (2018). Gradient symbolic representations in the output: a case study from Moses Columbian Salishan stress. NELS 48:1. 275-284.

Zimmermann, Eva (2019). Gradient symbolic representations and the typology of ghost segments. In Katherine Hout, Anna Mai, Adam McCollum, Sharon Rose \& Matt Zaslansky (eds.) Supplemental proceedings of the 2018 Annual Meeting on Phonology. http://dx.doi.org/10.3765/amp.v7i0.4576.

Zwicky, Arnold M. \& Geoffrey Pullum (1983). Cliticization vs. inflection: English n't. Lg 59. 502-513. 